NBER WORKING PAPER SERIES

\title{
MINIMUM STANDARDS AND INSURANCE REGULATION: EVIDENCE FROM THE MEDIGAP MARKET
}

\author{
Amy Finkelstein \\ Working Paper 8917 \\ http://www.nber.org/papers/w8917 \\ NATIONAL BUREAU OF ECONOMIC RESEARCH \\ 1050 Massachusetts Avenue \\ Cambridge, MA 02138 \\ May 2002
}

I am grateful to Daron Acemoglu, David Autor, Nancy Beaulieu, David Cutler, Peter Diamond, Sue Dynarski, Jon Gruber, Jerry Hausman, Melissa Schettini Kearney, Brigitte Madrian, Ben Olken, Jim Poterba, Andrew Sweeting, Sarah Reber, Tom Rice, and participants in seminars at Brookings, BU, Chicago GSB, Harvard, MIT, Yale, and the NBER Summer Institute for helpful comments. The views expressed herein are those of the author and not necessarily those of the National Bureau of Economic Research.

(C) 2002 by Amy Finkelstein. All rights reserved. Short sections of text, not to exceed two paragraphs, may be quoted without explicit permission provided that full credit, including $\mathbb{C}$ notice, is given to the source. 
Minimum Standards and Insurance Regulation: Evidence from the Medigap Market Amy Finkelstein

NBER Working Paper No. 8917

May 2002

JEL No. I18, I11, H51

\begin{abstract}
This paper examines the consequences of imposing binding minimum standards on the market for voluntary private health insurance for the elderly. Theoretically, the effect of these standards on insurance coverage and on welfare is ambiguous. I find robust evidence of a substantial decline in insurance associated with the minimum standards. The central estimates suggest that the standards are associated with an 8 percentage point ( 25 percent) decrease in the proportion of the population with coverage in the affected market; I find no evidence of substitution to other, unregulated sources of insurance coverage. Additional evidence suggests that the minimum standards are also associated with reduced coverage of non-mandated benefits among the insured. The empirical results are most consistent with a model of the effect of minimum standards on insurance markets with adverse selection, and suggest that adverse selection exacerbates the potential for unintended negative consequences of minimum standards. The final section of the paper considers the welfare implications of the changes in risk bearing associated with the minimum standards. The results suggest that the imposition of these standards was, even under relatively conservative assumptions, welfare reducing on net.
\end{abstract}

\author{
Amy Finkelstein \\ National Bureau of Economic Research \\ 1050 Massachusetts Avenue \\ Cambridge, MA 02138 \\ afinkels@nber.org
}


"We may tell the society to jump out of the market frying pan, but we have no basis for predicting whether it will land in the fire or a luxurious bed"

- George Stigler, The Citizen and the State: Essays on Regulation, 1975.

\section{Introduction}

Government intervention in insurance markets is both pervasive and varied. It runs the gamut from direct government provision of insurance through such programs as Social Security and Medicare, to government regulation of private insurance markets such as those for health and automobile insurance. An increasingly common form of private insurance market regulation is the imposition of minimum standards. These have been introduced in a range of insurance markets, including homeowner's and automobile insurance. Minimum standards have also been applied or proposed in several different health insurance markets, from state requirements that mental health benefits be included in employer-provided health insurance packages to Federal proposals for a "Patients' Bill of Rights" that would impose minimum standards on HMOs. ${ }^{1}$

In a perfect information, perfect competition model of insurance markets, there is no economic rationale for minimum standards, or indeed any government intervention. However, if these assumptions do not hold, government intervention may be efficiency-enhancing. For example, if consumers underestimate the probability of various risks, their voluntary insurance purchases will be sub-optimally low. Similarly, adverse selection can destroy the market for insurance completely or, short of that, result in sub-optimal amounts of insurance for certain risk classes. Minimum standards potentially counteract such tendencies for insufficient insurance coverage by setting a floor on the amount of insurance purchased by the insured.

As the Stigler quotation above suggests, however, the desire to solve potential private market failures must be balanced against the potential for unintended, negative consequences of minimum standards. A primary concern is that minimum standards will cause people to exit the

\footnotetext{
${ }^{1}$ Minimum standards are also a common form of intervention in markets other than insurance markets. These include, for example, minimum staff-child ratios in child care settings, and minimum safety standards in housing construction.
} 
market for the regulated insurance product. These people may either substitute toward unregulated forms of insurance or drop coverage altogether. An additional concern is that minimum standards may affect the equilibrium provision of non-mandated insurance benefits in the regulated insurance market.

The effect of the minimum standards on both the proportion of the population with insurance coverage and coverage of non-mandated benefit among the insured is theoretically ambiguous. Knowledge of the sign and magnitude of the response to minimum standards is therefore critical to evaluating the merits of this form of regulation. It can also shed light on the nature of the equilibrium - and particularly on the existence of potential market failures - in the unregulated market. Despite this, there is virtually no empirical evidence on the effect of minimum standards in insurance markets. ${ }^{2}$

In this paper, therefore, I examine the consequences of imposing large, binding minimum standards in the voluntary, private supplementary health insurance market for the elderly. Such insurance is commonly known as "Medigap" or "Medicare supplement insurance". These insurance policies cover some portion of the considerable medical costs not covered by Medicare, the public health insurance program for the elderly in the United States. In the late 1970s and early 1980s, almost all states followed a federal "recommendation" to impose minimum standards on the non-group Medigap market. The regulations specified certain gaps in Medicare coverage that any non-group Medigap policy must cover. They did not require that individuals purchase these policies, nor did they regulate their price. The coverage of other gaps was left to the market.

This paper has two main aims. First, I examine the empirical consequences of these minimum standards for insurance coverage. I also consider the welfare implications of the changes in risk bearing associated with these changes in insurance coverage. Second, I use the evidence of the effects of the minimum standards on the insurance market to distinguish among different models 
of the unregulated market equilibrium. Such an analysis provides a first step toward thinking about the likely consequences of alternative possible policies to address market failures in insurance markets.

The rest of the paper is organized as follows. In section two, I provide background on the Medigap market and the specific nature of the minimum standards imposed. Section three discusses a variety of theoretical mechanisms by which minimum standards may affect - in either direction - the proportion of the population with private insurance coverage and the amount of coverage for non-mandated benefits among those who retain insurance.

Section four presents the central empirical finding. I present robust evidence of a large "quality-quantity" tradeoff. The imposition of minimum standards is associated with a long-run decline in coverage in the regulated market (non-group Medigap policies) of 8 percentage points (25 percent). I find no evidence of substitution to the other potential sources of supplementary insurance coverage.

I then explore which models of the unregulated insurance market are consistent with the estimated effects of the minimum standards. Although I cannot definitively test the alternative theories, I draw on additional data to shed light on their relative merits. Section five presents evidence that suggests that the minimum standards are associated with substantial declines in non-mandated benefit coverage and in premiums among the insured in the regulated market. The magnitude of these effects appears inconsistent with a model of perfect markets and full information.

Section six explores other possible explanations for these estimated effects of the minimum standards. I find the most support for a model of the effect of minimum standards on insurance markets with adverse selection. This model suggests that adverse selection - which may provide an economic rationale for government intervention -exacerbates the potential for unintended,

\footnotetext{
${ }^{2}$ An exception is Gruber (1994) who finds no evidence of an effect of state-mandated benefits for employer-provided health insurance on insurance coverage. He notes, however, that the mandates were not
} 
negative effects of the minimum standards. These results therefore highlight the importance of considering how alternative forms of intervention might themselves interact with the market failure that they are designed to address.

The empirical results point to substantial declines in insurance coverage - on both the extensive and the intensive margin - associated with the imposition of binding minimum standards. Yet the mandated minimum benefits themselves provide considerable additional insurance for most individuals with non-group coverage. In section seven, I present estimates of the net changes in risk bearing associated with the minimum standards. I find that, even under relatively conservative assumptions, the minimum standards appear to be, on net, welfare reducing.

The last section concludes.

\section{Minimum standards in the Medigap market.}

\subsection{The Medigap market}

Virtually universal among the elderly in the United States, Medicare provides only partial health insurance coverage. In 1977, just before the minimum standards regulation, Medicare paid just under half of all health care expenses of the elderly. It is not surprising, therefore, that about two-thirds of Medicare beneficiaries had private insurance to supplement Medicare (Cafferata 1984). This Medigap insurance was obtained, in roughly equal proportions, from group and nongroup sources. ${ }^{3}$ The average annual premium for a non-group policy in 1977 was \$568 in 1999 dollars.

binding, and that this may explain the absence of an effect.

${ }^{3}$ Author's calculation based on data from the National Health Interview Surveys (NHIS) described in section four. Throughout this paper, I refer to health insurance purchased through a current or former employer or union as "group" insurance. I use the term "non-group" insurance to refer to non-employment related health insurance. This is purchased either directly through a private company or through a nonemployment related association such as the AARP. Non-group policies are sold on an individual basis. Group policies may include spousal dependents.

${ }^{4}$ Author's calculation based on data described in section five. Throughout this paper, dollar figures are reported in 1999 dollars - adjusted using the CPI-U - unless otherwise noted. 
The non-group market, to which the minimum standards applied, was highly concentrated. In 1984, Blue Cross and Blue Shield plans accounted for three-quarters of non-group Medigap premiums. Three companies accounted for over 50 percent of the remaining non-group premiums. (U.S. General Accounting Office, 1986).

Medigap covers some of the "gaps" in Medicare. Medicare consists of two different programs. Medicare Part A (Hospital Insurance Program) covers some non-physician inpatient hospital care expenses, and some care in skilled nursing facilities or home health care. Medicare Part B (Supplementary Medical Insurance Program) primarily pays physician fees for covered services.

Gaps in Medicare coverage fall into three main categories. First, there are cost-sharing provisions for the health services that Medicare covers. These include separate annual deductibles and copayments for expenses covered by Part A and by Part B. The $20 \%$ physician (part B) copayment is uncapped. The hospital (Part A) copayment increases with the length of the hospital stay. ${ }^{5}$ As a result, the cost sharing provisions leave the elderly with substantial exposure to medical expenditure risk. Second, there are certain health services that Medicare covers only partially and/or with severe restrictions, such as care in a skilled nursing facility or home health care. Third, there are health services that Medicare does not cover at all, such as outpatient prescription drugs and hospital stays beyond 150 days.

Two factors make the Medigap market a particularly attractive setting for studying the consequences of minimum standards in insurance markets. First, before the states adopted minimum standards, the non-group Medigap market was essentially unregulated (Van Ellet (1979), McCall, Rice and Hall (1983)). Most insurance markets have been heavily regulated for a long time, making it very difficult to isolate the consequences of one particular type of regulation. Second, the market failures that provide potential economic rationales for minimum standards 
may well be present in the Medigap market. Consumer misinformation, not only about medical risks but also about insurance needs, may be a problem for many Medigap consumers who must decide whether and how to supplement a public health insurance plan that they may not fully understand. Indeed, this was a major motivation for the minimum standards (see e.g. Merritt and Potemken 1982). Adverse selection - another potential rationale for minimum standards - is also present in the Medigap market (Ettner 1997).

\subsection{Minimum Standards: The Baucus Amendments}

Starting in the late 1970s, a small number of states introduced minimum standards for nongroup Medigap policies. In 1978, the National Association of Insurance Commissioners (NAIC) issued a set of model regulations for such minimum standards. The 1980 Federal Baucus amendments provided "encouragement" to the states to adopt these model regulations. ${ }^{6}$ Shortly thereafter, the remaining 42 states and the District of Columbia enacted minimum standards for non-group Medigap policies. Table 1 reports the first full year that the regulations were in effect in each state. ${ }^{7}$

The minimum standards applied only to non-group policies. They did not apply to policies purchased from a current or former employer or union ("group policies"). Policies that were converted from group policies to non-group policies, and renewals of existing non-group policies, were also not covered by the minimum standards. ${ }^{8}$

The minimum standards limited exclusions for pre-existing conditions to 6 months and specified a minimum set of benefits that policies must cover. Specifically, they required full coverage of the Part A copayments for hospital days covered by Medicare, and coverage of 90

\footnotetext{
${ }^{5}$ After the annual deductible, Medicare Part A fully covers all hospital inpatient expenses for 60 days, after which there is a copayment for hospital days 61-90, and another, higher copayment for hospital days 91150. Beyond 150 days, Medicare coverage of hospital stays ceases.

${ }^{6}$ Since insurance regulation is the prerogative of the states, the federal regulations were technically voluntary. Merritt and Potemken (1982) and McCall et al. (1983) describe the institutional structure established by the Baucus amendments to encourage states to adopt these regulations.

${ }^{7}$ Most states simply adopted the minimum standards in the model regulations. However, as indicated in Table 1, eight states adopted regulations that restricted the allowable policy space even further. I find no evidence of a differential effect of the more stringent regulations.
} 
percent of the cost of hospital stays beyond 150 days, at which point Medicare coverage ceases, for at least an additional 365 days. They also mandated full coverage of the Part B physician copayment, subject to a maximum deductible of \$200 and a maximum benefit of no less than $\$ 5,000$ (in nominal dollars). Finally, the policy had to cover the annual deductibles in both Part A and Part B for the first three pints of blood used, but not the general Part A and Part B deductibles. Appendix A provides more detail on the gaps in Medicare coverage and on the specific requirements of the minimum standards.

Two concerns motivated the passage of the Baucus amendments. First, policy-makers were worried that the elderly were unable to make informed choices about their insurance coverage; in particular, it was feared that they overestimated the amount of coverage provided through Medicare (see e.g. Merritt and Potemken 1982, DeNovo and Shearer, 1978, U.S. Senate, 1978). The minimum benefit standards described above were designed to address these concerns. In addition, concern about fraud and abuse practiced by a very small segment of the industry motivated several other provisions of the Baucus amendments, such as allowing the purchaser a 30 day "free look" period during which the policy could be returned, and requiring the prominent display of cancellation and termination clauses. In a similar vein, the legislation established loss ratio targets for Medigap policies that required the insurance company to return on average at least $75 \%$ of premiums collected from association policies and $60 \%$ of premiums collected from individual policies. In contrast to the minimum benefit standards, these policies affected only a few "rogue" companies and did not affect the vast majority of buyers in this highly-concentrated market. (McCall et al., 1983, Merritt and Potemken 1982, U.S. House of Representatives 1978). In the empirical analysis, I therefore attribute estimated effects of the reforms to the minimum benefit standards.

\subsection{The "bite" of the minimum standards}

\footnotetext{
${ }^{8}$ All non-group Medigap policies are sold on an annual basis.
} 
Data from the 1977 National Medical Care Expenditure Survey (NMCES) indicate that, prior to the enactment of the regulations, less than 7 percent of non-group policies in effect would have met the minimum standards that are measurable in these data. Ten years later, the 1987 National Medical Expenditure Survey (NMES) indicates the requirements were strongly enforced: 94 percent of individuals who had policies that were subject to the minimum standards met the measurable requirements. ${ }^{9}$ The most binding requirement was for coverage for 365 days beyond the first 150 hospital days - only 11 percent of non-group policies in 1977 would have met this requirement - followed by the requirement for full coverage of the Part B physician copayment, which only 52 percent of policies would have satisfied. In contrast, 70 percent covered the Part A copayments for hospital days 91-150, and 87 percent covered the Part A copayments for hospital days 61-90.

The potential out-of-pocket liability insured by the mandated benefits was substantial. The mandated coverage of the Part A hospital copayments provided insurance against rare but potentially catastrophic financial risks associated with long hospital stays. ${ }^{10}$ Moreover, mandated coverage of the 20 percent Part B copayment for physician charges insured an uncapped and potentially large exposed risk. I calculate that, on average, the amount of additional insurance required to upgrade a pre-reform plan to comply with the minimum standards was about one-fifth of the total amount of insurance in the pre-reform plan. ${ }^{11}$

\section{Minimum standards in a voluntary private insurance market}

\footnotetext{
${ }^{9}$ These estimates are based on information on compliance with all of the minimum standards except those regarding pre-existing conditions or coverage of the Part A and Part B blood deductibles. The data are described in more detail in section five.

${ }^{10}$ Data from a $20 \%$ sample of Medicare beneficiaries in 1984 indicate that only $0.1 \%$ of the elderly had hospital stays beyond 150 days. A stay of 365 days beyond the 150 days partially covered by Medicare would have cost an individual without private insurance \$170,638 (assuming a hospital charge of \$467.5 per day (American Hospital Association, 1978)).

${ }^{11}$ I compare risk premiums across insurance arrangements to quantify the difference in the amount of insurance. The data and method behind this type of calculation are described in more detail in section seven. The estimate reported here assumes a constant relative risk aversion utility function and a coefficient of relative risk aversion of 3 .
} 
This section describes the likely effects of the minimum standards under alternative models of the unregulated Medigap market, and discusses ways to distinguish empirically among the models. To begin, consider a 65-year-old, newly eligible for Medicare, who is deciding whether and how much supplementary health insurance to purchase, as shown in Figure 1. The budget constraint is given by the line $\mathrm{AB}$. Individuals who place a high value on insurance will purchase more comprehensive policies such as E, while those who value insurance less will choose a point such as D. Now suppose that the government imposes a minimum standard on the supplementary market. It does not require purchase of the supple mentary insurance, but it mandates that any purchase must be of at least the amount $m$. The individuals' budget set is now restricted to the point A and the solid line CB.

Consider first the baseline case of perfect competition, constant returns to scale, and perfect information. Under these assumptions, the regulation does not affect the relative price of health insurance. As a result, individuals whose insurance purchases already satisfy the minimum standards (i.e. they either purchase no insurance at point A or they purchase more than $m$, such as at point E) will experience no change in their consumption decisions. An individual who purchases less than $m$ (for example, at point $\mathrm{D}$ ), however, must now compare his utility from purchasing no insurance to his maximal utility from purchasing a policy that complies with the minimum standards. Assuming strictly convex preferences, if the individual chooses to purchase insurance, the optimal compliant policy is exactly the minimum required amount of insurance. As drawn, the individual now prefers purchasing no insurance (point A) to the optimal compliant policy (point C). Figure 1 thus illustrates how minimum standards can produce declines in the proportion of individuals with private insurance coverage and declines in welfare.

If we relax the baseline assumptions to allow for consumer misinformation or irrationality one of the major political motivations for the legislation - we might expect to see larger declines in Medigap coverage associated with the minimum standards. For if consumers mistakenly believe that Medicare covers some or all of the mandated benefits, they will underestimate the 
benefits from complying with the minimum standards. Consumers may also be more likely to drop non-mandated benefits in response to the minimum standards if they view the minimum benefit package as the recommendation of the government, or the default option. ${ }^{12}$ The presence of consumer misinformation suggests that the decline in Medigap coverage should be particularly acute among the less-educated, since they are likely to be the most misinformed about the gaps in Medicare coverage.

An important abstraction in Figure 1 is that it assumes that supplementary health insurance varies on only one dimension: quantity. In practice, Medigap policies are multi-dimensional. Policies that would not have met the minimum standards tended to cover a variety of nonmandated benefits. For example, in 1977, 98 percent of policies that would not have met the minimum standards covered the (non-mandated) Part A hospital deductible, and over one-fifth covered outpatient prescription drugs (also not mandated). ${ }^{13}$

We can therefore enrich the analysis to think of a three-good world: mandated insurance benefits, non-mandated insurance benefits, and all other goods. Under the same assumptions as above (perfect competition, constant returns to scale, and perfect information), individuals whose insurance policies already satisfy the minimum standards will not change their purchase of the non-mandated benefits. However, the model generates ambiguous changes in non-mandated benefits for individuals whose policies did not satisfy the minimum standards and who upgrade their policies to comply. The sign and magnitude of any changes in non-mandated benefits depends on both the income effects of the price increase associated with complying with the minimum standards and on whether the mandated and non-mandated benefits are complements or substitutes.

Another important abstraction in Figure 1 is that it ignores potential supply-side effects of the minimum standards. If we relax the assumptions of perfect competition, constant returns to scale

\footnotetext{
${ }^{12}$ Madrian and Shea (2001) show that default contribution rates and fund allocation have substantial effects on decisions about $401(\mathrm{k})$ savings.
} 
and symmetric information, a variety of supply side mechanisms can produce additional effects of the minimum standards on insurance coverage; these effects operate through the effect of the minimum standards on the pricing of insurance. On the one hand, the minimum standards may be associated with increased costs or markups, thus raising prices. Markups could increase if there is substantial insurance company exit in response to the minimum standards, or if these standards, by restricting the product space, facilitate collusion among the existing companies. Per-policy costs could increase if there are substantial joint costs in producing insurance policies; the minimum standards, by requiring that non-compliant policies be discontinued, could raise the share of joint costs born by the remaining compliant policies. These supply-side mechanisms can be examined directly by looking at changes in industry structure and in prices, and indirectly by looking at the effects of the reform on existing policyholders who were not subject to the minimum standards.

On the other hand, relaxing the assumption of perfect competition can produce mechanisms through which the introduction of minimum standards results in an increase in both the proportion of the population purchasing the regulated product and the provision of non-mandated benefits among the insured. For example, the Ronnen (1991) oligopoly model with differentiated products produces such results because the minimum standards enhance price competition by reducing the space over which firms can try to differentiate their products; in this model, the minimum standards are welfare enhancing.

Finally, we can relax the assumption of symmetric information. Consider a simple adverse selection model such as that of Akerlof (1970). In this setting, minimum standards can be welfare improving if the mandated minimum benefits are valued by each member of the insured population at or above his own actuarially-fair price, but cannot be purchased at this price in the unregulated market. By bundling the purchase of any non-mandated benefits with the mandated benefits, the minimum standards now make the mandated benefits available at the insured-

\footnotetext{
${ }^{13}$ Author's calculations based on 1977 NMCES.
} 
population average pooling price, and can thus produce increases in insurance coverage and in welfare. ${ }^{14}$ Even if some of the insured do not value the mandated benefits at the insuredpopulation average pooling price, they may still choose to upgrade their policies to comply with the minimum standards if their consumer surplus from the non-mandated benefits is sufficiently high. Of course, some lower risk individuals - if they have sufficiently low consumer surplus from the non-mandated benefits and value the mandated benefits at less than the insuredpopulation average pooling price - may choose to drop the non-mandated benefits rather than upgrade their policy to comply with the minimum standards. As a result, the Medigap market could unravel, producing substantial - perhaps complete - declines in insurance coverage and reducing the scope for welfare gains.

The next section presents the main empirical analysis: the effect of minimum standards on the proportion of the population with insurance coverage. I then explore which of these theoretical models are consistent with the empirical evidence.

\section{Effect of Minimum Standards on Proportion with Private Insurance Coverage}

\subsection{Data and Empirical Strategy}

I use repeated cross-sections from the National Health Interview Surveys (NHIS) to examine the effect of the minimum standards on the probability of being covered by non-group Medigap. The NHIS is an annual U.S. household survey. Supplementary questions on individuals' source of private health insurance (i.e. group or non-group), if any, were asked in the 1976, 1978, 1980, 1982, 1983, 1984, and 1986 NHIS. The earliest data therefore pre-date the introduction of the minimum standards in all but one of the states. The major drawback to the NHIS is that these data contain no information on health insurance premiums or on the benefits covered by the insurance. In the next section, I will turn to an alternative data source to examine the effect of the minimum standards on these other dimensions.

\footnotetext{
14 This is analogous to Akerlof's (1970) description of how a population-wide mandate for insurance coverage can be welfare improving if each individual values the insurance at or above his actuarially fair
} 
For the main analysis, I restrict the sample to individuals aged 65-68 who are covered by Medicare. ${ }^{15}$ I look only at these "young" old because these are the people who are most likely to be buying Medigap policies after the regulations went into effect. In additional analyses described below, I examine the effect on older age groups.

The binary dependent variable COVERAGE indicates whether the individual has non-group private health insurance, defined as insurance that was not "obtained through an employer or union." Individuals who do not have private health insurance or whose insurance was "obtained through an employer or union" are coded as not having non-group private health insurance. ${ }^{16}$ The main analysis pertains to non-group coverage rates since the regulations applied to this market. Further analysis described below indicates that coverage rates in the group market were not affected by the reform.

I exploit the substantial variation detailed in Table 1 in the timing of different states' adoption of the minimum standards to identify their effect on coverage rates in the non-group market. The empirical strategy compares non-group coverage rates after the reform has been imposed to nongroup coverage rates prior to its imposition, while controlling for other possible confounding changes. The basic estimating equation is:

COVERAGE $_{\mathrm{ijt}}=\alpha+\mathrm{STATE}_{\mathrm{j}}+\mathrm{YEAR}_{\mathrm{t}}+\mathrm{X}_{\mathrm{ijt}} \beta+\lambda \mathrm{ADOPT}_{\mathrm{jt}}+\varepsilon_{\mathrm{ijt}}$

STATE and YEAR are fixed effects that control respectively for any fixed differences across states in coverage rates and for any yearly changes in coverage rates that are common across states. $\mathrm{X}$ is a vector of covariates. It controls for observable compositional changes in the sample along dimensions that may be related to the propensity to hold non-group coverage. It consists of

\footnotetext{
price but cannot purchase insurance at this price in the unregulated market.

${ }^{15}$ I would like to further restrict the sample to those not on Medicaid and those without military health insurance. Unfortunately, data on these types of coverage are not available until the 1982 survey. Estimates of the effect of the reform using only data from 1982 and subsequent years do not differ from the estimates obtained using the whole sample and are not sensitive to whether those with Medicaid and military health insurance are excluded from the sample.

${ }^{16} 4 \%$ of the sample has both group and non-group coverage. For these individuals, COVERAGE is coded as 1 since the individual has non-group coverage. In results not reported here, I found that the estimated effect of the reform is not sensitive to how such individuals were coded.
} 
a series of dummies for gender, race (white or non-white), education (less than high school, high school graduate, some college, college graduate and higher), marital status (married or not), and self-reported health status (excellent, very good or good versus fair or poor).$^{17}$ It also includes a linear control for age. $\mathrm{ADOPT}_{\mathrm{jt}}$ is an indicator variable equal to 1 if the individual in state $\mathrm{j}$ and year $t$ is subject to the minimum standards regulation, and 0 otherwise. $\lambda$, the key parameter of interest, thus measures the estimated change in non-group insurance coverage rates associated with the implementation of the reform.

To examine the dynamics in the timing of the impact of the minimum standards, I enrich the basic specification to allow for separate short-term and long-term effects of the reform as follows: COVERAGE $_{\mathrm{ijt}}=\alpha+\mathrm{STATE}_{\mathrm{j}}+\mathrm{YEAR}_{\mathrm{t}}+\mathrm{X}_{\mathrm{ijt}} \beta+\lambda_{1} \mathrm{ADOPT}_{\mathrm{jt}, 1}+\lambda_{2} \mathrm{ADOPT}_{\mathrm{jt}, 2}+\varepsilon_{\mathrm{ijt}}$

$\mathrm{ADOPT}_{\mathrm{jt}, 1}$ is an indicator variable equal to 1 if it is the first or second year after adoption of the minimum standards in state $\mathrm{j} .{ }^{18} \mathrm{ADOPT}_{\mathrm{jt}, 2}$ is an indicator variable equal to 1 if it is three or more years after adoption of the minimum standards in state $\mathrm{j}$.

The identifying assumption in equations (1) and (2) is that, absent the reform, states would have had similar trends in Medigap coverage. I conduct a partial test of this identifying assumption by examining whether there are significant changes in coverage rates in the periods prior to the reform. I therefore estimate the following:

COVERAGE $_{\mathrm{ijt}}=\alpha+$ STATE $_{\mathrm{j}}+$ YEAR $_{\mathrm{t}}+\mathrm{X}_{\mathrm{ijt}} \beta+\lambda_{-2} \mathrm{ADOPT}_{\mathrm{jt},-2}+\lambda_{-1} \mathrm{ADOPT}_{\mathrm{jt},-1}+$ $\lambda_{1} \mathrm{ADOPT}_{\mathrm{jt}, 1}+\lambda_{2} \mathrm{ADOPT}_{\mathrm{jt}, 2}+\varepsilon_{\mathrm{ijt}}$

$\mathrm{ADOPT}_{\mathrm{jt},-1}$ is an indicator variable equal to 1 if it is two or three years prior to adoption and $\mathrm{ADOPT}_{\mathrm{jt},-2}$ is an indicator variable equal to 1 if it is 4 or more years prior to adoption. The omitted reference category is the year of adoption and the year prior to adoption (period 0). ${ }^{19}$

\footnotetext{
${ }^{17}$ I group health status this way because until 1982 the individual is given a choice of reporting their health status as "excellent", "good", "fair" or "poor." In 1982 and in subsequent years, the individual also has the option of reporting "very good".

${ }^{18}$ Because the data are, for the most part, biannual, I do not look at potential year-to-year differences in the effect of the reform.
} 


\subsection{Results}

Table 2 presents the results of estimating equations (1) and (2) by OLS. ${ }^{20}$ Columns (1) and (2) present the results of estimating equation (1) without and with covariates respectively. They indicate that the reform is associated with a 5.1 to 5.3 percentage point decrease in coverage. This effect is statistically significant at the 1 percent level and is not sensitive in magnitude or significance to the inclusion of covariates.

Column (3) examines the dynamics of the impact of the reform, using the specification in equation (2). The effect of the reform persists after it has been in place for 3 or more years, and indeed increases slightly. The reform is associated with a 4.9 percentage point reduction in coverage after 1 to 2 years and an 8.0 percentage point reduction after 3 or more years. Both of these estimates are statistically significant at the 1 percent level; they are also statistically significantly different from each other at the 10 percent level. ${ }^{21}$ The one-to-two-year phase-in may be due to a lag in enforcement or to the dynamics of adjustment to a new equilibrium. ${ }^{22}$

I examine whether the effect of the reform differs across observable characteristics of the individuals such as educational attainment, marital status, gender, race or health status. ${ }^{23}$ The only substantive or statistical differences - in either levels or proportions - are by race. The estimated

\footnotetext{
${ }^{19}$ The percentage of observations in each category ranges from 38 percent in $\mathrm{ADOPT}_{2}$ to 12 percent in $\mathrm{ADOPT}_{-1}$.

${ }^{20}$ All of the standard error estimates in section four allow for an arbitrary covariance matrix in the error structure within each state, as recommended by Bertrand, Duflo and Mullainathan (2002). The results are not sensitive to allowing an arbitrary covariance matrix in each state-year cell instead. The OLS estimates are also adjusted for heteroscedasticity in the linear probability model.

${ }^{21}$ The long run effects of the reform appear to be fully captured by allowing for differential effects of the reform in the first and second year compared to all later years. In results not reported here, I re-estimate equation (2) with separate indicator variables for the first and second year, the third and fourth year, the fifth and sixth year, and seven or more years that the reform has been in effect. All of these indicator variables are statistically significant at the 1 percent level, and their coefficients respectively are $-5.0,-7.2$, -11.0 and -8.1

${ }^{22}$ The fact that - with a sample of individuals aged 65 to 68 - more individuals may be buying policies under the new regulations as time passes does not appear to account for the larger long-run effect. In a sample of 65-year-olds, the long-run effect of the reform is still statistically significantly larger than the short-run effect.

${ }^{23}$ For health status I use both self-reported health status and a measure of activity limitation status. Because the activity limitation status measure changes in 1982, I do not include it as a covariate in the main analysis. When examining the differential effects of the reform by activity limitation status, I examine both the whole sample and the sub-sample from 1982 and later for which the measure is consistent.
} 
short- and long-run effects of the reform for whites (who make up approximately 90 percent of the sample) are smaller $(-0.045$ and -0.070 respectively) than for non-whites $(-0.084$ and -0.171 respectively). All of these estimates are statistically significant at the 1 percent level and the estimated long-run effect of the reform is statistically significantly smaller for whites than for non-whites at the 5 percent level. ${ }^{24}$ The larger impact of the reform on coverage rates for nonwhites is consistent with the fact that prior to the reform, non-whites tended to have substantially less coverage of non-mandated benefits than whites. ${ }^{25}$

Finally, I examine whether declines in non-group Medigap coverage associated with the minimum standards represent a net decline in insurance coverage or whether there is substitution toward alternative sources of supplementary insurance: public Medicaid and private group insurance. ${ }^{26}$ Table 3 reports the results of estimating equation (2) using first an indicator for group coverage and then an indicator for Medicaid coverage for the dependent variable. ${ }^{27}$ I find no evidence of substitution to either source of coverage associated with the minimum benefit standards. The Medicaid results are robust to restricting the sample to those in the lowest education category (who presumably are mostly likely to be eligible for Medic aid). This lack of substitution is not surprising given that group coverage and Medicaid tend to be both more comprehensive and cheaper than non-group coverage. The non-group market, presumably, consists of individuals without access to group insurance or Medicaid. ${ }^{28}$

\subsection{Specification checks}

\footnotetext{
${ }^{24}$ Since non-whites are less likely to have non-group coverage prior to the reform than whites (18 percentage points versus 34 percentage points), the proportional effects of the reform are even larger for non-whites than for whites

25 Author's calculation based on 1977 NMCES.

${ }^{26}$ Prior to the minimum standards, just under 10 percent of the sample had Medicaid coverage. Group coverage rates were similar to non-group coverage rates.

${ }^{27}$ I can only measure Medicaid coverage starting in 1982; the analysis of the effect of the minimum standards on Medicaid coverage is therefore restricted to data in 1982 and later years. The results for nongroup coverage reported above are robust to a similar restriction.

${ }^{28}$ Of course in the long-run, employers might have greater incentives to provide group health insurance coverage to those over age 65 as non-group coverage declines following the imposition of minimum standards. However, this is more likely to affect younger employees rather than those over age 65 , most of whom are retired, for whom the firm has little incentive to offer more attractive compensation packages.
} 
I perform several specification checks to test the robustness of the results in Table 2 and to investigate the validity of the identifying assumption. ${ }^{29}$ Appendix Table B1 indicates that the results are not sensitive to estimating equations (1) and (2) by probit, instead of by OLS. In results not reported here, I also find that the results are not sensitive to the particular age range for the "young" old chosen; the results are robust to using a sample of individuals aged 65 to 67 or 65 to 69 instead of the baseline sample of individuals aged 65 to 68 .

Table 4 reports results from several additional specification checks. The first column indicates that the results are robust to adding state-specific linear time trends to the basic specification in equation (2). The second and third columns show the results of estimating equation (3) without and with state-specific linear trends respectively. There is no evidence in either specification of changes in non-group coverage in periods prior to the reform relative to period 0 (the year of the reform and the year prior to the reform). This serves as partial confirmation of the identifying assumption that absent the introduction of the legislation, states would have had similar trends in Medigap coverage. It also suggests that the reforms were not adopted in response to pre-existing trends in non-group coverage rates.

The composition of states used to estimate the coefficient on any given $\mathrm{ADOPT}_{\mathrm{jt}, \mathrm{k}}$ varies with $\mathrm{k}$. For example, since the earliest year of data is 1976, the coefficient on $\mathrm{ADOPT}_{\mathrm{jt},-1}$ (two or three years before adoption), is identified only by individuals in states where the regulation's first full year in effect was 1978 or later. This could contaminate my results if the effect of the reform varies across states, or if the pre-period trends differ across states in ways not fully captured by a state-specific linear trend. To test for this, I re-estimate the model on two different balanced panels of states. In column (4), I re-estimate equation (3) using states in which regulations were first in effect in 1979 or later. In column (5), I re-estimate equation (2) using states in which

\footnotetext{
${ }^{29}$ The specification checks for Table 3 are not reported here, but are similarly supportive.
} 
regulations were first in effect in 1981 or earlier. ${ }^{30}$ The results are not sensitive to these restrictions. The results in columns (4) and (5) are also not sensitive to the inclusion of statespecific linear time trends (not reported).

\subsection{The magnitude of the effect of the reform}

Prior to the introduction of the minimum standards, 33 percent of the sample had non-group coverage. The estimates therefore indicate that the imposition of the minimum standards is associated with a 15 percent decline in non-group coverage in the first two years after implementation and a long-run reduction in coverage of almost 25 percent.

These estimates are within the broad range of findings that would be consistent with a fullinformation demand-side response to the minimum standards. Using detailed information on medical expenditures and sources of payment from the 1977 NMCES, I estimate that, ignoring moral hazard and adverse selection effects, the mandated Baucus benefits would have raised the expected payments (and hence an actuarially fair premium) for these policies by $\$ 168$, or 30 percent. If the marginal utility of complying with the mandate is zero, this predicted premium increase represents a 30 percent net tax on the purchase of non-group insurance. Under this assumption, the 25 percent decline in non-group insurance coverage is consistent with estimates of the price elasticity of demand for health insurance, which lie in the range of -0.5 to -1 (Cutler 1996). ${ }^{31}$ Of course, the marginal utility from the mandated insurance is likely to be positive, suggesting that the effect of the reform would be lower than the 15 to 30 percent decline in coverage predicted from a 30 percent net tax. On the other hand, accounting for administrative loads, insurance company profits and adverse selection suggests that the premium increase

\footnotetext{
${ }^{30}$ There is not sufficient variation in the timing of adoption in this sample to look separately at effects in various pre-periods, as in equation (3).

${ }^{31}$ Most estimates of the price elasticity of demand for health insurance are based on the demand response for comprehensive health insurance. The available evidence of the price elasticity of demand for supplementary health insurance suggests that it is in the low end of the range of estimated elasticities for comprehensive health insurance (Finkelstein, forthcoming).
} 
associated with complying with the mandated minimum benefits would likely be larger than the 30 percent calculated above. ${ }^{32}$

\section{Effect of Minimum Standards on Coverage of Non-Mandated Benefits and Premiums}

The previous section established that the minimum standards were associated with a large, robust, and statistically significant decline in the proportion of individuals with insurance coverage. While the magnitude of the decline is within the broad range of estimates that would be consistent with a full-information, demand-side response, the there are also a variety of additional mechanisms, discussed in section three, by which minimum standards could produce this result. To explore the evidence for these other mechanisms, I begin in this section by considering evidence of the effect of the minimum standards on other margins: coverage of non-mandated benefits and premiums.

\subsection{Data and Empirical Strategy}

For this analysis, I turn to a new data source: the 1977 National Medical Care Expenditure Survey (NMCES) and its companion survey, the 1987 National Medical Expenditure Survey (NMES). These data have the unique advantage of detailed data both on the benefits covered by an individual's Medigap policy and on the premiums for these policies. ${ }^{33}$ However, the long time period between these two cross-sections, which spans the adoption of the minimum standards in almost all states, makes the results of this section necessarily more speculative than those in the previous section. I use individuals with group Medigap insurance to try to control for other changes in the demand or supply of various Medigap benefits that may have occurred in the nongroup market during this 10-year period.

\footnotetext{
${ }^{32}$ For example, I calculate in the 1977 NMCES that the load on non-group Medigap policies, as measured by the excess of premiums over claims as a percentage of claims, is 60 percent. If this load is proportional to claims, then the expected premium increase associated with the mandated benefits would rise from 30 percent to approximately 50 percent.

33 Benefit information is obtained by contacting each individual's source of insurance for policy details and then coding up these details. This is considerably more reliable than self-reported benefit information.
} 
I limit the sample to Medicare recipients aged 65 to 71 who are policyholders of private health insurance and are not covered by Medicaid. The age cut is chosen in keeping with the results of the previous section, in which I found that individuals aged 65 to 68 were affected by the reform. ${ }^{34}$ I exclude individuals who are covered as dependents because dependents have the same benefits as policyholders and this would involve double counting. ${ }^{35} \mathrm{I}$ also limit the sample to those who are retired, defined as individuals who are not in the labor force. ${ }^{36}$ Finally, since the data are at the policyholder level, I exclude anyone who has both non-group insurance and group insurance (approximately 7 percent of the sample) because in such cases I cannot tell from which market a given benefit comes.

The empirical strategy is to compare changes in benefit coverage rates or in log premiums between 1977 and 1987 for privately insured individuals affected by the reform (i.e. those with non-group coverage) to changes for a control group of privately insured individuals who were not affected by the reform (i.e. those with group coverage).$^{37}$ The basic estimating equation is: $\mathrm{Y}=\beta_{1}$ AFTER $*$ NON-GROUP $+\beta_{2}$ AFTER $+\beta_{3} \mathrm{NON}-\mathrm{GROUP}+\mathrm{X} \beta_{4}+\mathrm{e}$

The dependent variable is either the log of premiums or a binary indicator of whether the individual's health insurance coverage includes a given benefit. The 1977 and 1987 data report the total annual premium per policyholder; since my sample is limited to individuals with only

\footnotetext{
${ }^{34}$ These data do not contain information on state of residence. But anyone who is 71 or younger in 1987 was no older than 68 in 1984 (the last year that was the first full year for regulation to be in effect in any state) and therefore is in the age group that I found was affected by the reform in the previous analysis.

${ }^{35}$ Non-group Medigap policies are sold on an individual basis while group Medigap policies may include spousal dependents. The results in this section are not sensitive to including individuals who are dependents on group Medigap policies in the sample.

${ }^{36}$ I make this restriction because federal legislation introduced in 1982 required that employers offer the same health insurance packages to employed workers under and over age 65 . This is not a severe restriction as most individuals over 65 are retired. The results in section four are not sensitive to this restriction.

${ }^{37}$ By 1977, four states had already introduced the minimum standards, three in 1976 . To the extent that the effect of these reforms was already partly felt by 1977 , the empirical strategy will underestimate the effect of the reform on non-mandated benefit coverage. An alternative empirical strategy would be to use individuals in these early states as a control group. Unfortunately, state identifiers are not available for the 1977 NMCES.
} 
one policy and without dependents, the premium reflects the per policy premium. ${ }^{38}$ The data also include measures of coverage for six different non-mandated benefits. Two benefits - coverage of the hospital (Part A) and physician (Part B) deductible - cover the remaining cost-sharing provisions in Medicare beyond those included in the mandated minimum package. The other four benefits cover home health care, care in a skilled nursing home, inpatient psychiatric care and out-patient prescription drugs.

NON-GROUP is an indicator variable that is 1 if the individual has a Medigap policy through the non-group market and 0 if the individual has a Medigap policy through the group market.

AFTER is an indicator variable for the year 1987. $\mathrm{X}$ is a matrix of covariates, similar to that used in section four, that controls for observed compositional changes that may be related to the propensity to hold various non-mandated benefits. ${ }^{39}$ The key variable of interest - AFTER*NONGROUP - measures changes in benefit coverage between 1977 and 1987 among those with nongroup Medigap relative to changes in benefit coverage over the same period for individuals with group Medigap.

Table 5 presents mean premiums and mean coverage rates for the six benefits in the nongroup and the group market in 1977 and in 1987. Premiums rose in real terms in both markets between 1977 and 1987, reflecting in part the increasing real cost of medical care. Between 1977 and 1987, benefit coverage rates in the non-group market are decreasing for all benefits except for care in a skilled nursing home. In the group market, benefit coverage rates are decreasing for the two deductibles but increasing for the other four benefits.

The changes over time in benefit coverage in the group market raise concerns about its appropriateness as a control for the changes in benefit coverage that would have occurred in the

\footnotetext{
${ }^{38}$ The premium is defined as the total premium; for the group market it therefore includes employer and employee contributions.

${ }^{39}$ It consists of dummies for gender, region of the country, whether the individual lives in an SMSA, race (white or non-white), marital status, education (less than high school, high school degree, some college, college degree or higher) and self-reported health status relative to others' their age. Age is also included linearly.
} 
non-group market absent the reforms. A primary concern is that increased adverse selection pressures over this period from the large increase in the mean and variance of medical expenditures might differentially affect benefit coverage in the group and non-group market. However, increases in adverse selection pressures should produce declines in benefits subject to severe adverse selection pressures, such as prescription drug coverage, which experienced an increase in coverage in the group market, and are less to produce declines in deductible coverage, which is where the group market experienced large declines.

More generally, other factors that might differentially affect these two markets - such as reductions in employer-provided retiree benefits - would tend to produce a uniform trend in benefit coverage in the group market, rather than the observed pattern of declines in some benefits and increases in others. I can also address the concern that the large increases in wage inequality during the period studied may have affected insurance demand differently for individuals in the group market, who tend to be of somewhat higher socio-economic status than those in the non-group market. ${ }^{40} \mathrm{I}$ allow the relationship between demographic covariates and benefit coverage to change over time by estimating an enriched version of equation (4) in which I interact all of the demographic covariates with AFTER. Tables 6 and 7 below show that the results are not sensitive to this specification.

Finally, I use the NHIS data to examine whether insurance coverage rates are trending similarly in the group and non-group markets in state-years prior to the introduction of the reforms. This provides a weak test of the identifying assumption that absent the reform, benefit coverage rates among the insured would have been on similar trends in the two markets. For each year $(1978,1980$, and 1982), I cannot reject the null hypothesis that the year fixed-effects are the same in the treatment group and the control group. Nor can I reject the joint hypothesis that all three year fixed effects are the same in the treatment group and the control group.

\subsection{Results}


Table 6 reports the difference-in-differences estimates of the change in benefit coverage in the non-group market relative to the change in benefit coverage in the group market. Columns (1) through (3) report the results without covariates, with covariates, and with interaction effects between the covariates and AFTER; the estimates are not sensitive to the specification. Appendix Table B2 indicates that the results are also not sensitive to estimation by probit rather than by OLS.

The first two rows of Table 6 report the results for the hospital and physician deductibles. The empirical strategy is, a priori, most convincing for these benefits for two reasons. First, the deductibles are arguably the benefits for which the 10 year time lag in the data is least troubling. It is harder to think of demand and supply shocks affecting deductible coverage than affecting coverage of other benefits for which the underlying nature of the risk being insured may well be changing over time. Second, the data in Table 5 indicate that the pre-treatment mean coverage rates in the non-group and group market were most similar for these two benefits. The results indicate that the minimum standards are associated with a large and statistically significant decline in coverage for the physician deductible but no change in coverage for the hospital deductible.

The last four rows of Table 6 indicate that the minimum standards are also associated with a substantial and statistically significant decline in the coverage of outpatient prescription drug benefits, inpatient psychiatric care, and home health care. The magnitude of the estimated declines in non-mandated benefits are quite large, ranging from 20 to 40 percentage point declines. There is weaker evidence of a decline in skilled nursing home care relative to the control group. In results not reported here, I find no evidence of systematic differences, either substantive or statistical, in the effect of minimum standards on non-mandated benefit coverage by observable characteristics.

\footnotetext{
${ }^{40}$ Author's calculations based on 1977 NMCES.
} 
To gauge the magnitude of the change in total expected insurance payments associated with the minimum standards, I estimate the effect of the minimum standards on total insurance premiums. $^{41}$ Table 7 shows the results of re-estimating equation (4) using the log of the premium as the dependent variable. The first three columns show the results respectively without controlling for individual characteristics, with controlling for them, and interacting them with AFTER. They indicate that the minimum standards are associated with an almost 50 percent decline in premiums in the non-group market relative to the group market. This suggests that the decline in expected payments from the decline in non-mandated benefits substantially outweighs the increase in expected payments from the inclusion of newly-mandated benefits. When additional controls are added for whether the policy covers each of the mandated and nonmandated benefits measurable in the data, column (4) indicates that the minimum standards are associated with an estimated 25 percent decline in premiums. This significant decline in premiums associated with the minimum standards - even after controlling for the benefit composition of the policy - is consistent with their being unmeasured declines in non-mandated benefits. $^{42}$

Even the estimated declines in measured non-mandated benefits among the insured are too large to be explained solely by demand-side mechanisms in a full information model of the Medigap market. ${ }^{43}$ While substitution effects may help explain declines in coverage for the physician deductible - which may be a substitute for coverage of the mandated physician copayment - they cannot explain declines in benefits such as inpatient psychiatric care and

\footnotetext{
${ }^{41}$ Assuming no changes in market structure, changes in premiums reflect changes in the expected payments from the insurance policy.

${ }^{42}$ Unmeasured declines in non-mandated benefits might include both declines in non-measurable, nonmandated benefits and declines in the comprehensiveness of coverage for measured non-mandated benefits for which we only observe whether or not there is any coverage and not the amount of coverage.

${ }^{43}$ Compositional changes associated with minimum standards in the pool of the privately insured might potentially explain the large declines in non-mandated benefits. However, as noted in section four, the minimum standards appear to be associated with larger declines in insurance coverage among individuals with less coverage of non-mandated benefits; if anything, therefore, compositional changes in the pool of the insured should have tended to produce an increase in coverage of non-mandated benefits among the remaining insured.
} 
prescription drug coverage which are more likely to be complements to the mandated coverage for hospital stays and doctor visits. Furthermore, the income effect from the mandated benefits is insufficient to explain the magnitude of the estimated decreases in non-mandated benefits. The $\$ 168$ actuarially fair increase in premiums that I estimate would be needed to upgrade policies to comply with the minimum standards represents only $0.8 \%$ of median income among those with non-group Medigap policies in the NMCES. Estimates of the income elasticity of demand for medical care range from 0.2 to 1 (Newhouse 1992). ${ }^{44}$ Given average non-group premiums in 1977 of $\$ 568$, even an income elasticity of demand of 1 would imply a decrease in demand for health insurance benefits of less than $\$ 6$. Yet the NMCES data suggest that the loss of the physician deductible coverage, alone, would result on average in a loss of health benefits of over five times this amount.

This suggests a role for factors other than a full-information demand response to the minimum standards. In the next section, I consider the three other factors discussed in section three that would tend to produce declines in insurance coverage from minimum standards: consumer misinformation, supply-side effects, and asymmetric information. I find the most evidence in support of a role for asymmetric information in explaining the impact of minimum standards on the Medigap market.

\section{Theoretical explanations for the estimated effect of these minimum standards}

\subsection{Consumer misinformation}

It is difficult to generate precise, testable, predictions for how consumer misinformation or limited rationality may affect the impact of minimum standards on insurance markets. As discussed in section three, consumer misinformation might be expected to magnify demand-side responses. Yet I find no strong empirical evidence in support of this explanation. In particular, there is no evidence that the minimum standards are associated with differential declines by

\footnotetext{
${ }^{44}$ Of course demand for medical care and demand for health insurance are not the same thing. But presumably the income elasticities are roughly similar.
} 
educational attainment in insurance coverage, on either the extensive or intensive margin, as might be expected if people with less education are more likely to be misinformed. Furthermore, the observed differential responses seem consistent with a rational response. For example, the finding that non-whites - who tended to have less comprehensive coverage of non-mandated benefits than whites - were more likely to drop coverage in response to the minimum standards is consistent with a rational response: the minimum standard requirements are a greater proportional tax on smaller policies.

\subsection{Supply-side effects of the minimum standards}

The large declines in insurance coverage associated with the minimum standards raise the possibility that the minimum standards were associated with substantial changes in market structure or market costs. Three pieces of evidence, however, suggest no large-scale changes of this nature. First, while there are no available data on insurance company market shares from the period under study, conversations with insurance regulators and insurance company executives from that era do not suggest widespread company exit associated with the minimum standards. Second, I can use data on individuals' insurance premiums and payments from private health insurance in the 1977 NMCES and 1987 NMES to compare loads on non-group and group policies before and after the introduction of the minimum standards. ${ }^{45} \mathrm{I}$ define the load in a particular market as the excess of average premiums over average claims as a percentage of average claims. These loads therefore reflect both the administrative costs of producing the insurance policy as well as insurance company profits. The load on non-group policies fell slightly between 1977 and 1987, from 60\% to 53\%. By contrast, it rose slightly in the group market, from $42 \%$ to $47 \%$. The decline in the load in the non-group market is not consistent with increased industry concentration or costs associated with the minimum standards, which should have been expected to produce increases in the load.

\footnotetext{
${ }^{45}$ Throughout section six, analysis of the 1977 NMCES and 1987 NMES is based on the sample defined in section five.
} 
Third, I can use the existing policyholders - who are not directly subject to the regulations to look for evidence of changes in market structure or costs. Individuals who bought their policies prior to the regulation could continue to renew their policies without having to make them compliant with the minimum standards. However, supply-side effects that produce increases in either markups or costs would be expected to affect the prices of these policies and hence produce declines in insurance coverage among existing policyholders. ${ }^{46}$

To test this, I return to the NHIS data and re-estimate equations (1) through (3) on the subsample of individuals who are 70 or older when the regulations went into effect and on the subsample of individuals who are 70-74 when the regulations went into effect. ${ }^{47}$ There is no evidence that the reform affected coverage for either of these older groups in either the short or long run; the coefficients on the ADOPT variables are all small in magnitude and statistically insignificant. This is consistent with the conventional wisdom that individuals tend to buy their Medigap policies shortly after becoming eligible for Medicare and then renew them without change; the older individuals would therefore not have become subject to the regulations. It is also not suggestive of large supply-side changes in response to the minimum standards.

\subsection{The effect of minimum standards in insurance markets with asymmetric information}

As discussed in section three, in a market with adverse selection, minimum standards can produce substantial declines in insurance coverage on both the intensive and extensive margin. Moreover, such a model is consistent with declines in non-mandated benefits that are substantially larger than demand-side responses based on income and substitution effects alone could generate, since the minimum standards may produce an unraveling of the market for the

\footnotetext{
${ }^{46}$ While individuals can renew their existing policies without becoming subject to the regulation, the price of the policy is not guaranteed and can therefore be raised in response to supply-side changes.

${ }^{47}$ For periods prior to the reform, the sample is limited to individuals 70 and over (or 70-74). For periods after the implementation of the reform, the sample is limited to individuals who would have been at least 70 (or 70-74) when the reform was implemented. Because of concern that the estimates may be biased by the aging of the sample within each state over time, I re-estimate equation (2) on the sub-sample of individuals who are 82 or older in each year; these individuals are all at least 70 in 1974 (the first year that regulations went into effect) in each year of data. The results are not sensitive to this alternative sample definition.
} 
non-mandated benefits. We can generate additional testable predictions of the effect of minimum standards in insurance markets with adverse selection by developing the model in more detail.

I adopt the standard framework in which competitive insurance markets respond to consumer private information by trying to design policies that separate individuals according to their risk type (Rothschild and Stiglitz (1976), Wilson (1977)). In a separating equilibrium, high risk individuals purchase full insurance coverage while incentive compatibility constrains low risk individuals to purchase less than full insurance. In such a setting, sufficiently high minimum standards may require the purchase of an amount of insurance above this incentive compatible amount. As a result, the separating equilibrium, and hence the ability to provide high risk types with comprehensive insurance in equilibrium, can be destroyed. In the Wilson (1977) model, if the minimum standards destroy the separating equilibrium, both types will pool at an amount of insurance above the minimum and less than the full insurance that high risk individuals were previously receiving. For sufficiently large minimum standards, the result can be a complete destruction of the market for policies with more insurance than the mandated minimum.

Appendix C develops the effects of minimum standards in the Wilson (1977) model in more detail. $^{48}$

Three additional empirical regularities are consistent with this model. First, Table 6 indicates that the minimum standards are associated with a large and statistically significant decline in coverage for the Part B physician deductible but no change in coverage for the Part A hospital deductible. Recall that, prior to the imposition of minimum standards, individuals were much more likely to have coverage for both the Part A hospital copayments (70-90\% depending on the length of stay) and the Part A hospital deductible (99\%) than for the analogous Part B physician cost sharing provisions (50\% and $85 \%$ respectively). In other words, individuals were more likely to be constrained from buying full insurance for the physician cost-sharing provisions than

\footnotetext{
48 These effects also obtain with the Grossman (1979) equilibrium (Neudeck and Podczeck (1996)) but not with the Miyazaki (1977) equilibrium (Encinosa, forthcoming).
} 
for the hospital cost-sharing provisions. The Wilson model predicts a collapse in comprehensive coverage if low risk individuals are constrained from buying such coverage in the unregulated private market equilibrium. It is therefore consistent with the Wilson model that the imposition of the requirements for coverage of the hospital and physician copayments should affect the market for full coverage of the physician cost-sharing provisions - for which not everyone had full coverage in the unregulated market - but not for the hospital cost-sharing provisions - for which almost everyone had comprehensive coverage prior to the regulations.

Second, the stylized Wilson (1977) model predicts that mandated minimum benefits can produce a switch from a separating equilibrium to a pooling equilibrium. A less knife-edge version of this prediction is that we should see a decrease in the amount of dispersion in plan types associated with the introduction of the minimum standards. ${ }^{49}$ The empirical evidence supports this prediction. Obviously, the entire policy space, and hence policy dispersion, will shrink mechanically when minimum standards are imposed. However, there is no mechanical reason for any change in the dispersion of non-mandated benefits included in different plans. I therefore define a plan based on which of the non-mandated benefits measurable in the data are covered. This produces about 20 different plans purchased in a given year and market. Between 1977 and 1987, the NMCES and NMES data indicate that the Herfindahl measure of plan concentration almost doubles in the non-group market (from 0.11 to 0.21 ) while remaining constant in the group market (at 0.12 ) ${ }^{50}$ Figure 2 shows plan market share by plan rank (from highest to lowest market share) in the non-group market prior to the introduction of the minimum standards (1977), and after their introduction (1987). The empirical cumulative distribution function of plan shares in the non-group market in 1987 lies everywhere above the 1977 empirical cumulative distribution function; there is no such clear ranking of the two periods in the

\footnotetext{
${ }^{49}$ We can move away from the knife-edge predictions of the Wilson (1977) model by, for example, allowing for consumer heterogeneity in risk aversion.
} 
group market (not shown). Using McFadden's (1989) test for first order stochastic dominance, I am unable to reject the null hypothesis that the 1977 distribution of plan shares in the non-group market first order stochastic dominates the 1987 distribution in the non-group market. I can reject this null in the group market, however, at the 10 percent level.

Third, the Wilson (1977) model suggests that the market for comprehensive, full-insurance plans can be completely destroyed by the minimum standards. This suggests that more comprehensive policies become even more adversely-selected after the imposition of the minimum standards. I test for this by examining whether premiums rise more between 1977 and 1987 on more comprehensive non-group policies relative to less comprehensive non-group policies. ${ }^{51}$ The final column of Table 7 shows the results of re-estimating the model estimated in column (4) with the addition of an interaction term between AFTER*NON-GROUP and the number of non-mandated benefits in the policy ("BENEFITS"). BENEFITS ranges from 0 to 6 and averages 3.4. The regression also includes indicator variables for whether each measurable mandated and non-mandated benefit is covered by the policy. As predicted, the interaction term in column (4) is positive and significant, indicating that the minimum standards are associated with larger premium rises (or, more accurately, smaller premium decreases) on more comprehensive plans relative to less comprehensive plans in the non-group market relative to the group market.

Thus several independent pieces of evidence are consistent with the impact of minimum standards in a Wilson (1977) model of an insurance market with adverse selection. However, the lack of a finding of a differential response to the minimum standards on either coverage margin by health status - as measured either by self-reported health status or activity limitation status -

\footnotetext{
${ }^{50}$ An increase in plan concentration does not necessarily indicate an increase in insurer market concentration. Insurers tend to sell multiple plans and therefore the increased prevalence of some plans does not necessarily favor certain firms.

51 The model predicts that marginal people (i.e. the lowest risk people in each plan type) will move from more comprehensive to less comprehensive plans. Cutler and Zeckhauser (2000) discuss the implications of such a change for the relative pricing of insurance contracts. They note that since the distribution of
} 
seems inconsistent with the Wilson model, which makes sharp predictions of differential responses to the minimum standards based on private information about health status (see Appendix C). More generally, observable characteristic s such as education may in fact proxy for private information about health status since such characteristics are correlated with health but were not widely used in pricing Medigap policies. ${ }^{52}$ Yet we observe no evidence of differential effects of the reform by these characteristics. This may reflect the difficulty of empirically distinguishing that portion of risk which is truly private information from that portion which the insurance company can proxy for by pricing based on age and gender and selectively denying coverage to certain types. It also raises the interesting question of why insurance companies choose to price based on so little information, if in fact - as seems likely - other observable characteristics are predictors of risk type. I regard this as a natural challenge for future work.

\section{Welfare Implications}

This final section considers the welfare implications of the estimated effects of the minimum standards. The empirical results point to substantial declines in insurance coverage - on two margins - associated with the minimum standards. Yet compliance with the minimum standards themselves provides, on average, substantial additional insurance coverage. If markets function perfectly and individuals make fully rational insurance purchase decisions, any changes in insurance coverage associated with the minimum standards - whether increases or decreases represent welfare losses. Minimum standards may be welfare-enhancing, however, if the unregulated insurance market results in sub-optimally low private insurance purchases.

As discussed at the outset, consumer misinformation or adverse selection may produce such sub-optimal coverage rates. The former was a major political motivation for the regulations; the latter is consistent with the preponderance of the empirical evidence presented above of the 
effects of minimum standards. Both suggest the interpretation of insurance gains as welfare gains and insurance losses as welfare losses ${ }^{53}$ The net welfare effect of the minimum standards depends on the relative magnitudes of the welfare gains and losses associated with the minimum standards. I quantify these effects by simulating the risk distribution under alternative insurance arrangements and evaluating the welfare changes associated with changes in risk exposure.

\subsection{Changes in risk bearing associated with changes in insurance coverage}

The estimates are based on the sample of 989 Medicare recipients in the 1977 NMCES who are not on Medicaid and who have private, non-group insurance. ${ }^{54}$ The NMCES provides individuatlevel data on health expenditures and sources of payment for several different health expenditure categories. Figure 3 shows the distribution of out-of-pocket medical expenditures under four different insurance arrangements. The solid black bars show this distribution for those with non-group private health insurance coverage prior to the reforms. The other three bars simulate the medical expenditure distribution under alternative insurance arrangements for these individuals. The simulations are done by adjusting the portion of particular expenses paid out-ofpocket and those paid by private insurance to reflect the change in insurance coverage. ${ }^{55}$ All of

\footnotetext{
${ }^{52}$ Conversations with people familiar with the Medigap market in the period studied indicate that most pricing was done based solely on age; pricing based on gender, and - even more rarely - smoking status, was also sometimes done.

${ }^{53}$ If the government believes that individuals purchase insufficient insurance prior to the regulations, then from the government perspective, increases in insurance represent welfare gains while decreases represent welfare losses. Of course, from the individual perspective, since individuals believe they are optimizing and the minimum standards do not change their information set, the regulations must be welfare reducing. The welfare effects of insurance changes associated with the minimum standards in a model with adverse selection are discussed in more detail in Appendix C.

${ }^{54}$ None of these people has a hospital stay beyond 150 days. So that the welfare benefit from the mandated coverage for such stays is not undervalued, I adjust the risk distribution in my sample to take account of the fact that data from a $20 \%$ sample of Medicare beneficiaries in 1984 indicates that $0.1 \%$ of the elderly have hospital stays in excess of 150 days.

${ }^{55}$ An alternative approach to these simulations would be to estimate the changes in risk faced by different types of individuals using the difference-in-differences empirical approach of section five. The difficulty with this approach, however, is the estimation of the change in risk distribution associated with losing nongroup coverage. A comparison of the medical expenditure distribution of those with insurance in 1977 to those with no insurance in 1987 conflates the effects of insurance coverage with compositional differences in the medical expenditure risk faced by the pool of people with and without insurance; a comparison of these differences in the 1977 NMCES data suggests that they are non-trivial.
} 
these calculations assume that total medical expenditures are unaffected by the change in insurance status. ${ }^{56}$

A comparison of the solid black bars with the adjacent speckled bars shows the increased risk of out-of-pocket medical expenditures, particularly at the high end of the distribution, associated with losing pre-reform coverage. The bars with horizontal lines indicate the medical expenditure risk distribution when pre-reform plans are upgraded as necessary to comply with the minimum standards; compared to the distribution under the pre-reform plans (sold black bars), out-ofpocket expenditures in the upgraded plans are lower at every expenditure decile. This comparison provides an upper bound on the increase in insurance associated with the minimum standards for those who maintained coverage since it ignores decreases in non-mandated benefits associated with the minimum standards.

Unfortunately, the health expenditure categories in the NMCES are not detailed enough to simulate the change in risk exposure associated with the declines in coverage for the nonmandated benefits estimated in section five. I can, however, simulate the distribution of medical expenditure risk if all insurance except for the mandated minimum benefits is dropped. This is shown by the gray bars, which provide a lower bound for the increase in insurance coverage associated with the minimum standards for those who maintained coverage.

\subsection{Computing the welfare implications of these changes in risk bearing}

To calculate the magnitude of the welfare changes associated with the changes in risk bearing shown in Figure 3 requires several additional assumptions. ${ }^{57}$ I assume that utility is a function of non-health consumption $(c)$ and a random variable $m$, which measures out-of-pocket medical expenditure. I assume that the utility function takes the form $u(c-m)$. Changes in private insurance coverage affect the probability density function of out-of-pocket medical expenditures,

\footnotetext{
${ }^{56}$ Moral hazard is unlikely to have as much effect on private insurance expenditures in the Medigap market compared to other insurance markets since most of the moral hazard costs of Medigap are born by the public Medicare program rather than by private insurers (Ettner 1997).
} 
$f(m)$, and thus expected utility, which is given by $\int_{0}^{\bar{m}} u(c-m) f(m) d m$. I assume a constant relative risk aversion utility function and abstract from the possibility of state-dependent utility functions.

The risk premium $(\pi)$ measures the maximum amount that a risk averse individual would be willing to pay to comple tely insure against the random variable $m . \pi$ is defined implicitly by:

(5) $u(c-\pi)=\int_{0}^{\bar{m}} u(c-m) f(m) d m$

For each individual in the data, I calculate the risk premium implicitly defined by equation (5) under different insurance arrangements. For each insurance arrangement, I use the empirical distribution of out-of-pocket medical expenditures summarized in Figure 3 for $f(m)$, and the individual's income for $c .^{58}$

This calculation entails several important simplifying assumptions. First, it considers only private welfare and ignores public welfare losses from the negative moral hazard externality that the private policies exert on the public Medicare program. Second, it assumes that individuals are identical with respect to health risks and preferences. In practice, the response to the minimum standards will be related to how much individuals value their insurance coverage; this suggests that a calculation based on identical individuals will overstate net welfare losses. ${ }^{59}$ Finally, the calculation ignores the existence of de-facto partial insurance for long hospital stays and other

\footnotetext{
57 This calculation closely follows Feldstein and Gruber (1995). More details on the calculation can be found there.

${ }^{58}$ Following Feldstein and Gruber (1995), I adjust the different distributions of medical expenditure risk to keep their mean constant. Any change in the mean risk should be captured in a change in premium and thus is simply a transfer between the insurer and the insured.

${ }^{59}$ How great an issue this is depends on the amount of dispersion in risk aversion in the population. Like estimates of mean risk aversion, estimates of the dispersion vary considerably. For example, Halpern and Hausman (1986) estimate a normal distribution for the coefficient of relative risk aversion and find a mean of 3.5 and a standard deviation of 0.17. Barsky et al. (1997) estimate a log normal distribution and find a mean risk tolerance of .24 with a standard deviation of 0.33 .
} 
very expensive medical events. ${ }^{60}$ Since coverage for long hospital stays was one of the mandated benefits and was rarely held prior to the introduction of minimum standards, the welfare calculation may overstate the welfare gains associated with the insurance provided by the minimum standards and thus understate the net welfare losses associated with the minimum standards.

Table 8 reports the average change in welfare across individuals associated with moving from the pre-reform status quo to a new insurance status. This welfare change is represented by the risk premium under the pre-reform insurance plans minus the risk premium under the new insurance status. An increase in the risk premium reflects an increase in the individual's exposed risk and is therefore associated with a decrease in welfare. I report results for two coefficients of relative risk aversion: 1 (i.e. log utility) and 3. The estimates of welfare changes increase (in absolute value) as risk aversion increases.

The average welfare loss associated with losing pre-reform coverage ranges from $\$ 37$ to $\$ 943$ per person (column 1). The average welfare gain associated with upgrading pre-reform plans to comply with the minimum standards, without altering the provision of non-mandated benefits, ranges from $\$ 4$ to $\$ 196$ (column 2). The estimates presented in column 3 indicate that changing from pre-reform insurance plans to insurance plans that cover only the mandated minimum benefits results in an average welfare loss of $\$ 29$ to $\$ 734$.

To calculate the average net welfare change associated with the regulations, I average the welfare changes associated with different types of insurance changes using the 25 percent longrun estimate for the proportion of the insured who lost coverage. Even under the conservative assumption that there was no decrease in non-mandated benefits among those who retain insurance coverage, this calculation (based on columns 1 and 2) suggests an average net welfare

\footnotetext{
${ }^{60}$ This may be provided by states' medically needy programs (which provide Medicaid to elderly individuals who have high medical expenses relative to their income in a given year), by the provision of uncompensated care to the indigent by some hospitals, and by the federal income tax system's co-insurance of large medical expenses.
} 
loss ranging from $\$ 6$ for a coefficient of relative risk aversion of 1 to $\$ 89$ for a coefficient of relative risk aversion of $3{ }^{61}$ This loss represents 10 to 15 percent of the average welfare gains associated with having the pre-reform coverage (i.e. the negative of the results in column 1). Since approximately one-third of the 22 million Medicare beneficiaries in 1977 had private, nongroup coverage, this suggests an aggregate welfare loss of \$40 million to \$587 million associated with imposing these minimum standards on the non-group market for private supplementary health insurance for the elderly.

\section{Conclusion}

This paper has examined the consequences of imposing large, binding minimum standards on a voluntary private health insurance market. Despite the widespread application of minimum standards in insurance markets, their theoretical effects are ambiguous and little is known empirically of their consequences. I find that the minimum standards are associated with a substantial decline in insurance coverage. The central estimate suggests a $25 \%$ long-run decline in insurance coverage in the regulated market associated with imposing minimum standards. There is no evidence of substitution from the regulated market to alternative sources of insurance.

Additional evidence suggests that the minimum standards are associated with reduced coverage for many of the non-mandated benefits among those who retain insurance.

A model of the effect of minimum standards in insurance markets with asymmetric information appears to be the best candidate to explain these effects. This model, as well as the concerns about consumer misinformation that were the political motivation for the regulation, suggest that insurance gains associated with the minimum standards can be interpreted as welfare gains, and insurance losses as welfare losses. Therefore, the welfare implication of these minimum standards depends on how welfare gains associa ted with upgrading plans to comply with the minimum standards compare to welfare losses for those who dropped coverage or

\footnotetext{
${ }^{61}$ Under the liberal assumption that all of the non-mandated benefits were dropped, the estimated average
} 
reduced coverage of non-mandated benefits. I estimate that, even under relatively conservative assumptions, these minimum standards are associated with a net welfare loss.

These findings have important implications for government intervention in insurance markets. In particular, they highlight the need to think carefully about the nature of the market failure that motivates the intervention, and how it affects the impact of government intervention in the private market. One of the key findings is that market failures that may motivate government intervention can also magnify the scope of the unintended negative consequences of this intervention. In this case, the insurance losses associated with imposing minimum standards were exacerbated by the presence of asymmetric information.

More generally, the results of this paper suggest that a fruitful direction for further work would be to consider - both theoretically and empirically - how alternative forms of government intervention in insurance markets interact with the second-best equilibrium in the unregulated market. For example, a natural alternative to minimum standards in the voluntary Medigap market is for the government to extend the mandatory coverage requirements in the Medicare program. The findings in this paper suggest that in evaluating the merits of mandatory coverage, it is important to consider how the level of coverage provided by the public program may affect the equilibrium in the private market for supplementary coverage, and in particular how it may affect adverse selection pressures in that private market.

net welfare losses (based on columns 1 and 3) rise to $\$ 31$ and $\$ 786$ respectively. 


\section{References}

Akerlof, George. 1970. "The Market for "Lemons": Quality, Uncertainty and The Market Mechanism”. Quarterly Journal of Economics (74): 488-500.

American Hospital Association. A.H.A. Guide to the Health Care Field. Chicago, IL, 1978.

Barsky, Robert B, F. Thomas Juster, Miles S. Kimball, and Matthew D. Shapiro. 1997. "Preference Parameters and Behavioral Heterogeneity: An Experimental Approach in the Health and Retirement Study." Quarterly Journal of Economics (112): 537-580.

Bertrand, Marianne, Esther Duflo and Sendhil Mullainathan. 2002. "How Much Should We Trust Differences-in-Differences Estimates?” NBER Working Paper 8841.

Cafferata, Gail Lee. 1984. "Private Health Insurance Coverage of the Medicare Population." National Health Care Expenditures Study, Data Preview 18. DHHS Publication No. (PHS) 843362. U.S. Department of Health and Human Services.

Cafferata, Gail Lee. 1985. "Private Health Insurance of the Medicare Population and the Baucus Legislation.” Medical Care, 23(9):1086-96. September.

Chiappori, Pierre-Andre. 2000. Econometric Models of Insurance under Asymmetric Information. In Georges Dionne, ed. Handbook of Insurance Economics. London: Kluwer.

Cutler, David. 1996. "Comment" to "Fundamental Tax Reform and Employer-Provided Health Insurance," Jonathan Gruber and James Poterba, in Economic Effects of Fundamental Tax Reform, H. Aaron and W. Gale (eds), Washington: Brookings Institution, pp.125-162.

Cutler, David and Richard Zeckhauser. 2000. The Anatomy of Health Insurance, in The Handbook of Health Economics, Culyer AJ and Newhouse JP (eds).

DeNovo, Anne and Gail Shearer. 1978. Private Health Insurance to Supplement Medicare. Office of Policy Planning, Federal Trade Commission.

Encinosa, William. Forthcoming. A comment on Neudeck and Podczeck's "Adverse Selection and Regulation in Health Insurance Markets." Journal of Health Economics.

Ettner, Susan. 1997. Adverse selection and the purchase of Medigap insurance by the elderly. Journal of Health Economics (16): 543-562.

Feldstein, Martin and Jonathan Gruber. 1995. A Major Risk Approach to Health Insurance Reform. NBER Reprint No. 2151.

Finkelstein, Amy. Forthcoming. The effect of tax subsidies to employer-provided supplementary health insurance: evidence from Canada. Journal of Public Economics.

Fox, Peter D., Thomas Rice and Lisa Alecxih. 1995. "Medigap Regulation: Lessons for Health Care Reform." Journal of Health Politics, Policy and Law. Vol. 20, No. 1, Spring. pp 31-48 
Grossman, H. 1979. Adverse selection, dissembling and competitive equilibrium, Bell Journal of Economics, 10:336-343.

Gruber, Jonathan. 1994. State-mandated benefits and employer-provided health insurance. Journal of Public Economics 55: 433-464.

Halpern, Janice and Jerry Hausman. 1986. Choice Under Uncertainty: A Model of Applications for the Social Security Disability Insurance Program. Journal of Public Economics, 31: 131-161.

Madrian, Brigitte. 1994. The Effect of Health Insurance on Retirement. Brookings Papers on Economic Activity, 1, pp.181-232.

Madrian, Brigitte and Dennis Shea. 2001. The Power of Suggestions: Inertia in 401(k)

Participation and Savings Behavior. Quarterly Journal of Economics: (116) (4):1149-1187.

McCall, Nelda, Thomas Rice and Arden Hall. 1983. Medigap: Study of Comparative Effectiveness of Various State Regulations: Final Report. SRI International. Menlo Park, CA.

McCormack, Lauren A., Peter D. Fox, Thomas Rice and Marcia Graham. 1996. "Medigap Reform Legislation of 1990: Have the Objectives Been Met?" Health Care Financing Review, Fall, Volume 18, Number 1. pp.157-174.

McFadden, Daniel. 1989. Testing for Stochastic Dominance. In Studies in the Economics of Uncertainty, Thomas Fomby and Tae Kun Seo (eds), New York: Springer-Verlag, pp.113-134.

Merritt, Richard E. and Donna B. Potemken (eds). 1982. Medigap: issues and update. The Intergovernmental Health Policy Project, George Washington University, Washington D.C. June.

Miyazaki, Hajime. 1977. The rate race and internal labor markets. Bell Journal of Economics 8 (Autumn), pp.394-418.

Neudeck, Werner and Konrad Podczeck. 1996. Adverse selection and regulation in health insurance markets. Journal of Health Economics, (15): 387-408.

Newhouse, Joseph P. 1992. “Medical Care Costs: How Much Welfare Loss?” Journal of Economic Perspectives, 6(3): 3 -21.

P.L. 96-265. Jun 9, 1980. "Voluntary Certification of Medicare Supplemental Health Insurance Policies." [a.k.a. The Baucus Amendments]

Rice, Thomas, Marcia Graham and Peter Fox. 1997. The Impact of Policy Standardization on the Medigap Market. Inquiry 34: 106-116, Summer.

Ronnen, Uri. 1991. "Minimum quality standards, fixed costs, and competition." RAND Journal of Economics Vol 22, No. 4, pp. 490 - 504.

Rothschild, Michael and Joseph Stiglitz. 1976. An Essay on the Economics of Imperfect Information. Quarterly Journal of Economics 90 (November), pp.629-649. 
Stigler, George. 1975. The Citizen and The State: Essays on Regulation. Chicago: University of Chicago Press.

U.S. General Accounting Office. 1986. Medigap Insurance: Law Has Increased Protection Against Substandard and Overpriced Policies. Pub. No. GAO/ HRD-87-8. Washington D.C.

U.S. General Account Office. 1991. Medigap Insurance: Better Consumer Protection Should Result from 1990 Changes to Baucus Amendment. Pub. No. GAO/HRD-91-49. Washington D.C.

U.S. House of Representatives, Select Committee on Aging. 1978. Abuses in the Sale of Health Insurance to the Elderly in Supplementation of Medicare: A National Scandal. Comm. Pub. No. 95-160. Washington DC

U.S. Senate, Special Committee on Aging. 1978. "Medi-Gap: Private Health Insurance Supplements to Medicare." Hearing before the Special Committee on Aging, United States Senate, June 29, 1978. U.S. Government Printing Office, Washington D.C.

Van Ellet, T. (ed). 1979. Medigap: State Responses to Problems with Health Insurance for the Elderly. The Intergovernmental Health Policy Project, George Washington University, Washington D.C. October 30.

Wilson, Charles. 1977. A model of Insurance Markets with Incomplete Information. Journal of Economic Theory 16, pp.167-207. 
Table 1: Implementation of Minimum Standards for Non-Group Medigap Policies

\begin{tabular}{lll}
\hline $\begin{array}{l}\text { First Full Year of } \\
\text { Regulations in Effect }\end{array}$ & STATES & $\begin{array}{l}\text { Percentage of } \\
\text { National Health } \\
\text { Interview Survey } \\
\text { Sample }^{62}\end{array}$ \\
\hline 1974 & CA* & 9.7 \\
\hline 1977 & IL, CT, MN* & 8.1 \\
\hline 1979 & RI, PA, WI* & 9.1 \\
\hline 1980 & MA** & 2.5 \\
\hline 1981 & GA, OR, FL, NH, NV, VT, NE, WY* & 10.9 \\
\hline 1982 & IA, SC, AK, AZ, CO, AL, ND, UT, NJ, AR, & 27.0 \\
\hline & VA*, WV*, NY*, WA, TN & 28.5 \\
\hline 1983 & ME, HI, IN, KS, OK, OH, ID, MS, DE, KY, \\
\hline 1984 & TX, MT, MO, SD, NM, LA, NC, MD & \\
\hline
\end{tabular}

* Denotes regulation that established classes of policies each with their own minimum benefit standards. In all of these cases, the least comprehensive category had minimum benefit standards as strict or stricter than the Baucus requirements, and with the addition of other benefits came other requirements.

** Denotes standardization. Three policies, specified in detail, were the only ones that could be sold. The least comprehensive policy satisfied the Baucus criteria.

Sources: The above table was compiled based on information in Van Ellet (1979), Merritt and Potemken (1982), McCall, Rice and Hall (1983), U.S. General Accounting Office (1986), and conversations with state regulators in Massachusetts and Wisconsin.

\footnotetext{
${ }^{62}$ This sample is described in detail in section four.
} 


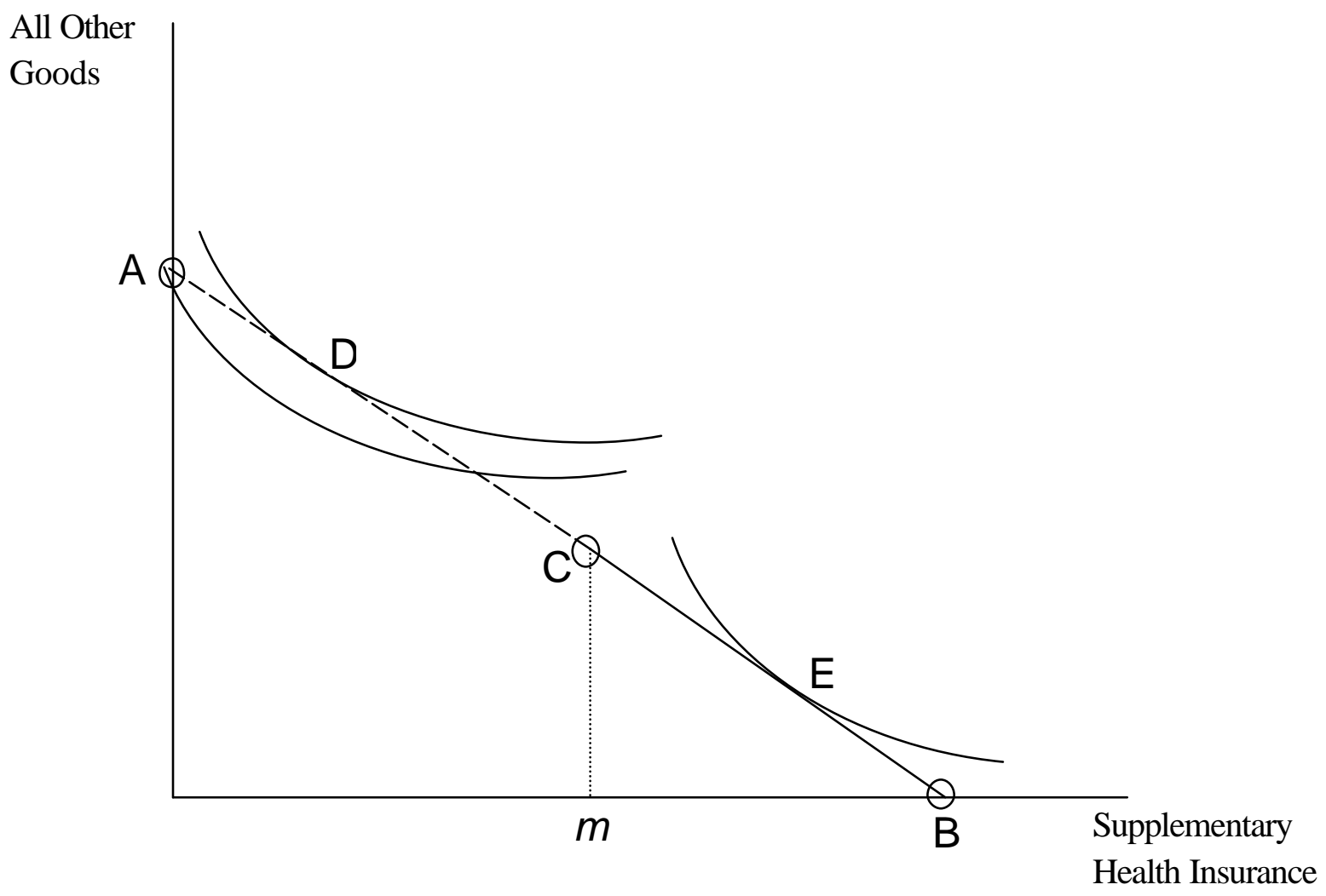

Figure 1: The effect of minimum standards on the decision to purchase insurance 
Table 2: Effect of Minimum Standards on Non-Group Coverage Rate

(1)

\begin{tabular}{ll}
\hline ADOPT (After Adoption) & $\mathbf{- 0 . 0 5 1} * * *$ \\
& $\mathbf{( 0 . 0 1 4 )}$
\end{tabular}

ADOPT $_{1}(1$ or 2 Years

After Adoption)

ADOPT $_{2}$ (3 or More

Years After Adoption)

State Fixed Effects

Year Fixed Effects

Age

Male

Married

High School Degree

Some College

College Degree of Higher

White

Health Status Excellent, Very Good or Good

Constant

$0.425 * *$

(0.011)

$\mathrm{R}^{2}$

$\mathrm{N}$

0.031

17,649
(2)

(3)

\section{$-0.053 * * *$ \\ (0.014)}

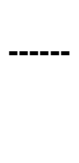

YES

YES

$0.016^{* * * *}$

(0.003)

$-0.066 * * *$

(0.007)

$-0.014$

(0.010)

$0.025 * *$

(0.011)

0.012

(0.013)

$-0.025$

(0.017)

$0.150 * * *$

(0.015)

$0.025 * *$

(0.010)

$-0.757 * * *$

(0.190)

0.048

17,317
$-0.049 * * *$

(0.010)

$-\mathbf{0 . 0 8 0} * * *$

(0.022)

YES

YES

$0.016^{* * * *}$

(0.003)

$-0.066^{* * *}$

$(0.007)$

$-0.014$

(0.010)

$0.025 * *$

(0.011)

0.012

(0.013)

$-0.026$

(0.017)

$0.150 * * *$

(0.015)

$0.025 * *$

(0.010)

$-0.754 * * *$

(0.191)

0.048

17,317

Notes: Coefficients in columns (1) and (2) are from OLS estimation of equation (1) using the 1976 through 1986 NHIS data. Coefficients in column (3) are from OLS estimation of equation (2) on the same data. The dependent variable is whether an individual has coverage in the non-group market. Sample is limited to those aged 65 to 68 . Standard errors are in parentheses. They are adjusted for the heteroscedasticity in the linear probability model and allow for an arbitrary covariance matrix within each state over time. $* * *$ denotes significance at the $1 \%$ level. $* *$ denotes significance at the $5 \%$ level. * denotes significance at the $10 \%$ level. The omitted education category is less than high school diploma. The omitted health category is "fair or poor." 
Table 3: Effect of Minimum Standards on Coverage by Alternative Sources of Supplementary Insurance

Group Coverage $\quad$ Medicaid Coverage $\quad$ Medicaid Coverage;

Sample limited to

individuals with less than

high school education

\begin{tabular}{llll}
\hline ADOPT $_{1}$ (1 or 2 Years & 0.012 & 0.009 & 0.017 \\
After Adoption) & $(0.015)$ & $(0.012)$ & $(0.022)$ \\
& & & 0.031 \\
ADOPT $_{2}$ (Three or More & -0.001 & 0.021 & $(0.027)$ \\
Years After Adoption) & $(0.013)$ & $(0.015)$ & 0.135 \\
& & & 3,986 \\
$\mathrm{R}^{2}$ & 0.101 & 0.113 & high \\
$\mathrm{N}$ & 17,332 & 9,224 & \\
\hline
\end{tabular}

Notes: Coefficients are from OLS estimation of equation (2). Column headings give the dependent variable. The first column is estimated using the 1976 through 1986 NHIS data. Since information on Medicaid coverage is available only in 1982 and later years, the other two columns are estimated using the 1982 through 1986 NHIS data. Standard errors are in parentheses. They are adjusted for the heteroscedasticity in the linear probability model and allow for an arbitrary covariance matrix within each state over time. $* * *$ denotes significance at the $1 \%$ level. $* *$ denotes significance at the $5 \%$ level. $*$ denotes significance at the $10 \%$ level. All regressions include a full set of covariates and state and year fixed effects. Sample is limited to those aged 65 to 68 .

Table 4: Effect of Minimum Standards on Non-Group Coverage Rate: Specification Checks

\begin{tabular}{|c|c|c|c|c|c|}
\hline & Full Sample & Full Sample & Full Sample & $\begin{array}{l}\text { States with } \\
\text { Reforms First in } \\
\text { Effect } 1979 \text { or } \\
\text { Later }\end{array}$ & $\begin{array}{l}\text { States with } \\
\text { Reforms First in } \\
\text { Effect } 1981 \text { or } \\
\text { Earlier }\end{array}$ \\
\hline & (1) & (2) & (3) & (4) & (5) \\
\hline $\begin{array}{l}\mathrm{ADOPT}_{-2}(4 \text { or More } \\
\text { Years Prior to } \\
\text { Adoption) }\end{array}$ & ------- & $\begin{array}{l}0.011 \\
(0.018)\end{array}$ & $\begin{array}{l}-0.009 \\
(0.045)\end{array}$ & $\begin{array}{l}0.020 \\
(0.029)\end{array}$ & $\begin{array}{l}------ \\
\end{array}$ \\
\hline $\mathrm{ADOPT}_{-1}$ (Two or & & 0.0002 & -0.006 & 0.007 & \\
\hline $\begin{array}{l}\text { Three Years Prior to } \\
\text { Adoption) }\end{array}$ & ------ & $(0.014)$ & $(0.019)$ & $(0.017)$ & ------ \\
\hline $\mathbf{A D O P T}_{1}(1$ or 2 & $-0.045 * *$ & $-0.049 * * *$ & $-0.044 * *$ & $-0.051 * *$ & $-0.053 *$ \\
\hline $\begin{array}{l}\text { Years After } \\
\text { Adoption) }\end{array}$ & $(0.017)$ & $(0.014)$ & (0.019) & $(0.021)$ & $(0.026)$ \\
\hline $\begin{array}{l}\text { ADOPT }_{2} \text { (Three or } \\
\text { More Years After } \\
\text { Adoption) }\end{array}$ & $\begin{array}{l}-0.078 * * \\
(0.032)\end{array}$ & $\begin{array}{l}-0.081 * * * \\
(0.021)\end{array}$ & $\begin{array}{l}-0.075 * * \\
(0.035)\end{array}$ & $\begin{array}{l}-\mathbf{0 . 0 7 0} \\
(0.043)\end{array}$ & $\begin{array}{l}-0.081 * * * \\
(0.023)\end{array}$ \\
\hline $\begin{array}{l}\text { State-specific Linear } \\
\text { Trends }\end{array}$ & YES & $\mathrm{NO}$ & YES & NO & $\mathrm{NO}$ \\
\hline $\mathrm{R}^{2}$ & 0.052 & 0.048 & 0.052 & 0.050 & 0.038 \\
\hline $\mathrm{N}$ & 17,317 & 17,317 & 17,317 & 14,329 & 6,950 \\
\hline
\end{tabular}

Notes: Coefficients in columns (1) and (5) are from OLS estimation of equation (2) using the 1976 through 1986 NHIS data; the ADOPT variables are interpreted relative to the entire period prior to adoption. Coefficients in column (2) through (4) are from OLS estimation of equation (3) on the same data; the ADOPT variables are interpreted relative to period 0. The dependent variable is whether an individual has coverage in the non-group market. Sample is limited to those aged 65 to 68. Standard errors are in parentheses. They are adjusted for the heteroscedasticity in the linear probability model and allow for an arbitrary covariance matrix within each state over time. $* * *$ denotes significance at the $1 \%$ level. $* *$ denotes significance at the $5 \%$ level. $*$ denotes significance at the $10 \%$ level. All regressions include a full set of covariates and state and year fixed effects. 
Table 5: Mean Benefit Coverage Rates and Premiums in Non-Group and Group Market

\begin{tabular}{|c|c|c|c|c|}
\hline \multirow[b]{2}{*}{ Benefit Coverage } & \multicolumn{2}{|c|}{ Non-Group Market } & \multicolumn{2}{|c|}{ Group Marke } \\
\hline & 1977 & 1987 & 1977 & 1987 \\
\hline Premiums (\$1999) & 568 & 831 & 1,498 & 3,369 \\
\hline Hospital Deductible & 0.99 & 0.91 & 0.95 & 0.87 \\
\hline Physician Deductible & 0.85 & 0.39 & 0.91 & 0.72 \\
\hline Outpatient Prescription Drug & 0.27 & 0.21 & 0.79 & 0.91 \\
\hline Care in Skilled Nursing Home & 0.62 & 0.75 & 0.46 & 0.68 \\
\hline Inpatient Psychiatric Care & 0.36 & 0.05 & 0.67 & 0.75 \\
\hline Home Health Care & 0.19 & 0.05 & 0.28 & 0.53 \\
\hline
\end{tabular}

Note: Data are from the 1977 NMCES and 1987 NMES. All means are weighted.

Table 6: Effect Of Minimum Standards on Non-Mandated Benefit Coverage

\begin{tabular}{|c|c|c|c|}
\hline " Benefit Coverage & Without Covariates & With Covariates & $\begin{array}{l}\text { With Covariates and } \\
\text { with Interactions } \\
\text { between Covariates and } \\
\text { AFTER } \\
\text { (3) }\end{array}$ \\
\hline Hospital Deductible & $\begin{array}{l}0.0007 \\
(0.034) \\
{[\mathrm{N}=1,042]}\end{array}$ & $\begin{array}{l}0.004 \\
(0.036) \\
{[\mathrm{N}=940]}\end{array}$ & $\begin{array}{l}-0.006 \\
(0.039) \\
{[\mathrm{N}=940]}\end{array}$ \\
\hline Physician Deductible & $\begin{array}{l}-0.269 * * * \\
(0.054) \\
{[\mathrm{N}=1,045]}\end{array}$ & $\begin{array}{l}-0.237 * * * \\
(0.057) \\
{[N=943]}\end{array}$ & $\begin{array}{l}-0.241 * * * \\
(0.061) \\
{[\mathrm{N}=943]}\end{array}$ \\
\hline Outpatient Prescription Drug & $\begin{array}{l}-0.177 * * * \\
((0.051) \\
{[\mathrm{N}=1,130]}\end{array}$ & $\begin{array}{l}-0.198 * * * \\
(0.054) \\
{[\mathrm{N}=1,015]}\end{array}$ & $\begin{array}{l}-0.186^{* * *} \\
(0.059) \\
{[\mathrm{N}=1,015]}\end{array}$ \\
\hline Care in Skilled Nursing Home & $\begin{array}{l}-0.091 \\
(0.061) \\
{[\mathrm{N}=1,165]}\end{array}$ & $\begin{array}{l}-0.110^{*} \\
(0.064) \\
{[\mathrm{N}=1,047]}\end{array}$ & $\begin{array}{l}-0.103 \\
(0.066) \\
{[\mathrm{N}=1,047]}\end{array}$ \\
\hline Inpatient Psychiatric Care & $\begin{array}{l}-0.389 * * * \\
(0.055) \\
{[\mathrm{N}=1,165]}\end{array}$ & $\begin{array}{l}-0.389 * * * \\
(0.058) \\
{[\mathrm{N}=1,047]}\end{array}$ & $\begin{array}{l}-0.359^{* * *} \\
(0.059) \\
{[\mathrm{N}=1,047]}\end{array}$ \\
\hline Home Health Care & $\begin{array}{l}-0.396^{* * *} \\
(0.054) \\
{[\mathrm{N}=1,165]}\end{array}$ & $\begin{array}{l}-0.404 * * * \\
(0.057) \\
{[N=1,047]}\end{array}$ & $\begin{array}{l}-0.389 * * * \\
(0.058) \\
{[N=1,047]}\end{array}$ \\
\hline
\end{tabular}

Note: Data are from the 1977 NMCES and 1987 NMES. Table reports the estimated coefficient on AFTER*NON-

GROUP from estimation of equation (4) by OLS. Different rows correspond to different dependent variables.

Heteroscedasticity-adjusted standard errors are in parentheses. *** indicates significance at the $1 \%$ level; ** indicates significance at the 5\% level; * indicates significance at the $10 \%$ level. 
Table 7: Effect of the Minimum Standards on Log Premiums

\begin{tabular}{|c|c|c|c|c|c|}
\hline & (1) & (2) & (3) & (4) & (5) \\
\hline AFTER*NON-GROUP & $\begin{array}{l}-\mathbf{0 . 4 8 1} * * * \\
(0.098)\end{array}$ & $\begin{array}{l}-0.468 * * * \\
(0.094)\end{array}$ & $\begin{array}{l}-0.454 * * * \\
(0.099)\end{array}$ & $\begin{array}{l}-0.254 * * \\
(0.107)\end{array}$ & $\begin{array}{l}-\mathbf{- 0 . 5 0 1} * * * \\
(0.151)\end{array}$ \\
\hline AFTER & $\begin{array}{l}0.997 * * * \\
(0.085)\end{array}$ & $\begin{array}{l}0.982 * * * \\
(0.081)\end{array}$ & $\begin{array}{l}0.032^{(+)} \\
(1.58)\end{array}$ & $\begin{array}{l}-0.933^{(+)} \\
(1.51)\end{array}$ & $\begin{array}{l}-0.845^{(+)} \\
(1.50)\end{array}$ \\
\hline NON-GROUP & $\begin{array}{l}-0.881 * * * \\
(0.082)\end{array}$ & $\begin{array}{l}-0.800 * * * \\
(0.081)\end{array}$ & $\begin{array}{l}-0.813 \\
(0.086)\end{array}$ & $\begin{array}{l}-0.574 * * * \\
(0.094)\end{array}$ & $\begin{array}{l}-0.580 * * * \\
(0.094)\end{array}$ \\
\hline $\begin{array}{l}\text { Controls for Individual } \\
\text { Characteristics }\end{array}$ & NO & YES & YES & YES & YES \\
\hline $\begin{array}{l}\text { Interactions between Individual } \\
\text { Characteristics and AFTER }\end{array}$ & NO & NO & YES & YES & YES \\
\hline Controls for Each Benefit & NO & NO & NO & YES & YES \\
\hline $\begin{array}{l}\text { AFTER*NON- } \\
\text { GROUP*BENEFITS }\end{array}$ & ----- & ----- & ------ & ----- & $\begin{array}{l}0.105^{* *} \\
(0.053)\end{array}$ \\
\hline $\begin{array}{l}\mathrm{R}^{2} \\
\mathrm{~N}\end{array}$ & $\begin{array}{l}0.491 \\
1,165\end{array}$ & $\begin{array}{l}0.534 \\
1,047\end{array}$ & $\begin{array}{l}0.545 \\
1,047\end{array}$ & $\begin{array}{l}0.551 \\
937\end{array}$ & $\begin{array}{l}0.553 \\
937\end{array}$ \\
\hline
\end{tabular}

Note: Table reports the results from estimation of equation (4) by OLS, with the log of the premium as the dependent variable. BENEFITS is a variable that measures the number of non-mandated benefits in the policy; it ranges from 0 to 6 .

Heteroscedasticity-adjusted standard errors are in parentheses. *** indicates significance at the $1 \%$ level; ** indicates significance at the 5\% level; * indicates significance at the 10\% level. Data are from the 1977 NMCES and 1987 NMES.

Figure 2: Market Share of Non-Group Plans

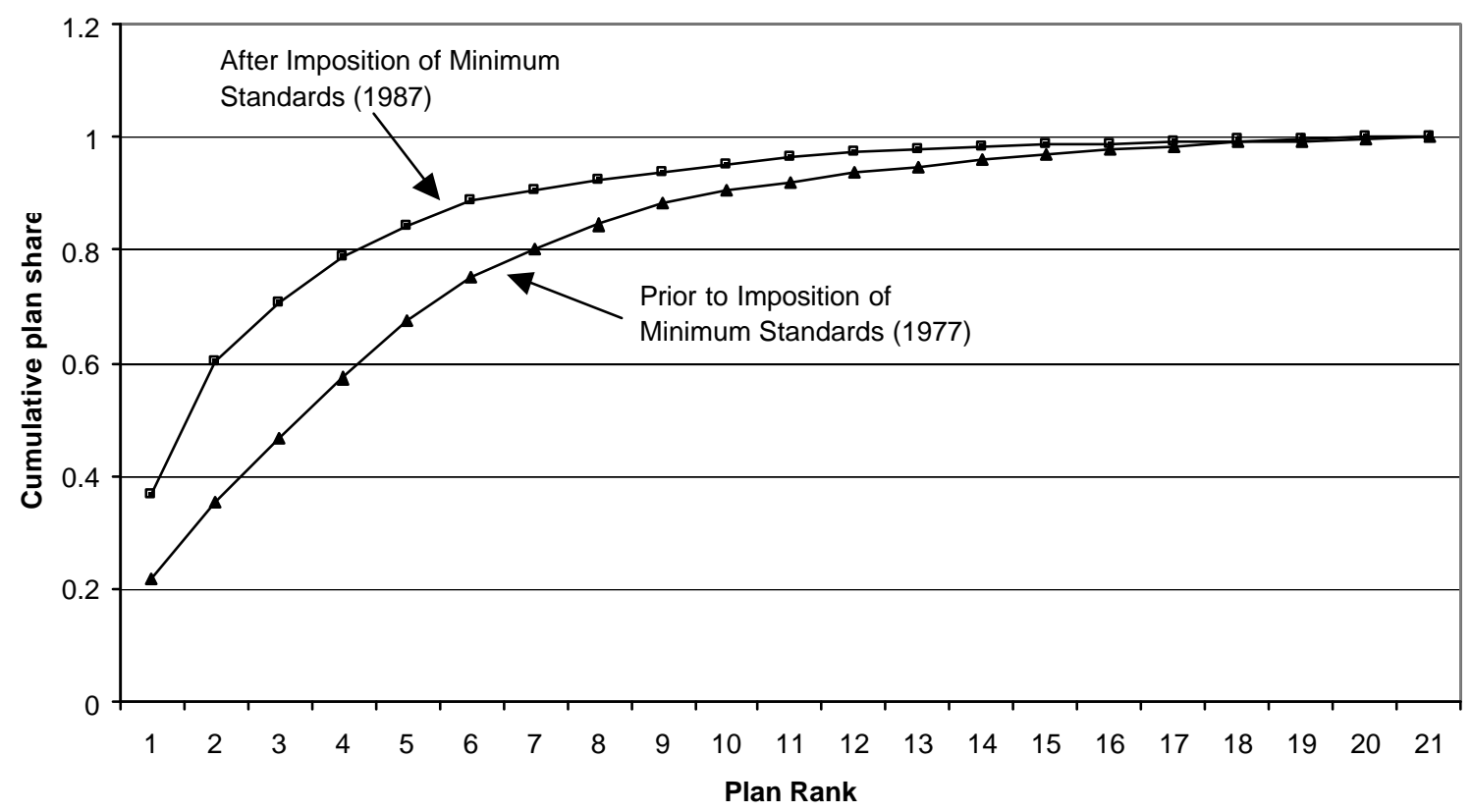

${ }^{(+)}$This coefficient reflects the coefficient for the reference category, given all of the interactions of AFTER and individual characteristics described in the text. 
Figure 3: Distribution of Out of Pocket Medical Expenditures Under Different Insurance Arrangements

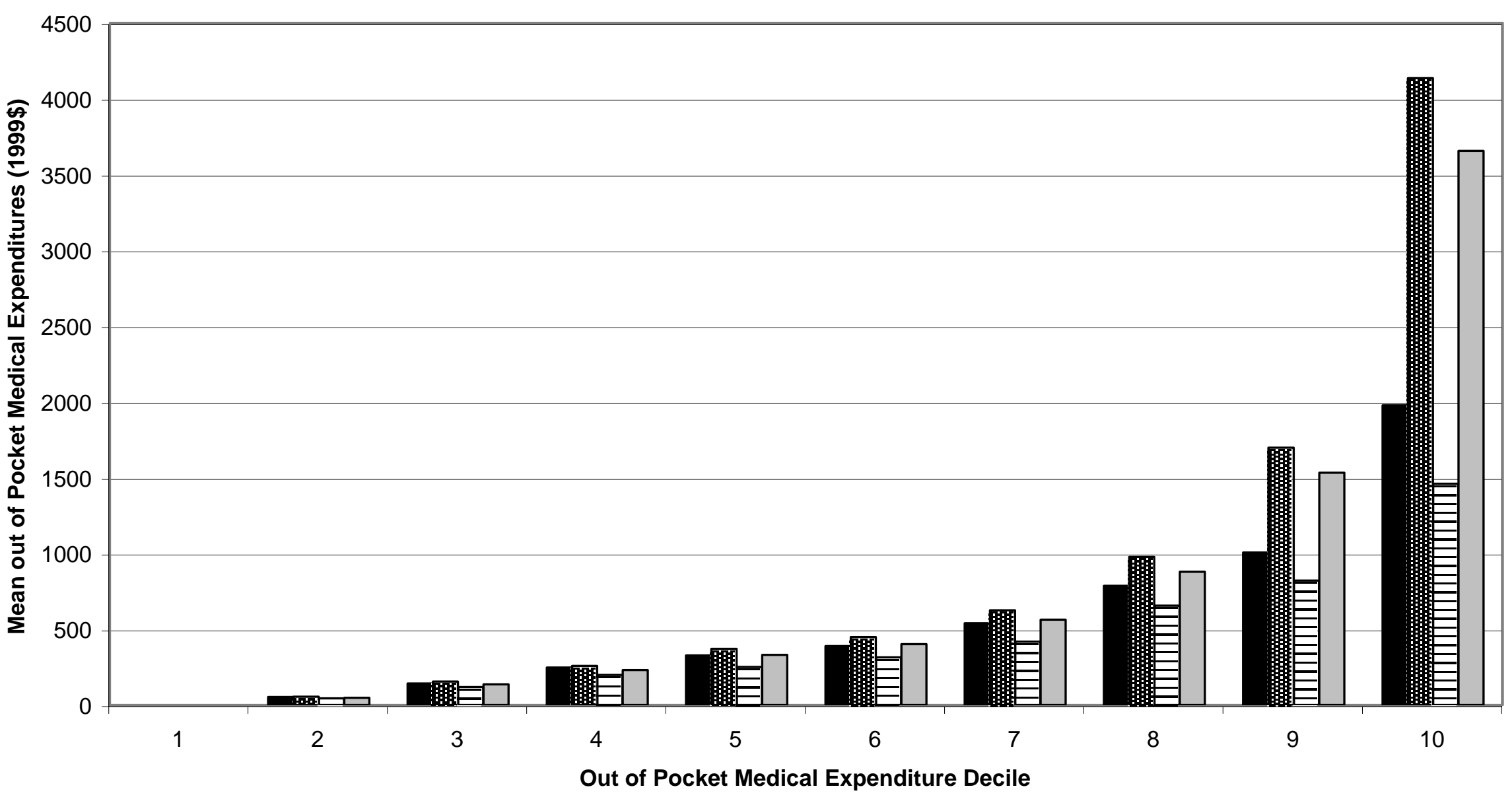

Dre-Reform Insurance Plans 国 No Private Insurance

日Pre-Reform Plans, Upgraded to Meet Minimum Standards $\square$ Insurance Covering Mandated Benefits Only 
Table 8: Welfare Change Associated with Insurance Plan Changes (1999 \$)

\begin{tabular}{llll}
\hline \hline $\begin{array}{l}\text { Coefficient of } \\
\text { Relative Risk } \\
\begin{array}{l}\text { Aversion } \\
1\end{array}\end{array}$ & $\begin{array}{l}\text { Losing pre-reform } \\
\text { coverage }\end{array}$ & $\begin{array}{l}\text { Upgrading pre-reform } \\
\text { plans to comply with } \\
\text { requirements }\end{array}$ & $\begin{array}{l}\text { Upgrading pre-reform plans to comply } \\
\text { with requirements but dropping all non- } \\
\text { mandated benefits }\end{array}$ \\
\hline 3 & $(1)$ & $(2)$ & $(3)$ \\
\hline \hline
\end{tabular}

Note: Table entries indicate the negative of the change in risk premium associated with a moving from the pre-reform insurance status quo to a new insurance arrangement. Changes in risk premiums are reported in 1999 dollars. 


\section{Appendix A: Gaps in Medicare (1977-1987)}

Bolded benefit gaps are those that the minimum standards required non-group policies to provide.

I. $\quad$ Cost Sharing Provisions in Medicare

A. Part A (Hospital)

1. Annual Deductible. (\$341 in 1977; $\$ 764$ in 1987)

2. Copayment for hospital days $61-90$ ( $\$ 85$ per day in $1977 ; \$ 191$ per day in 1987 )

3. Copayment for lifetime reserve hospital days $91-150$ ( $\$ 170$ per day in $1977 ; \$ 382$ per day in 1987) ${ }^{63}$

4. Annual Deductible for first three pints of blood used in the hospital

B. Part B (Physician)

1. Annual Deductible ( $\$ 165$ in $1977 ; \$ 110$ in 1987)

2. $20 \%$ Copay for approved physician charges ${ }^{64}$

3. Annual Deductible for first three pints of blood used.

II $\quad$ Services Covered Only Partially / With Restrictions By Medicare

1. Care in a Skilled Nursing Facility

2. Home Health Care Visits

3. Inpatient psychiatric care

III. Services Not Covered By Medicare

1. Outpatient prescription drugs

2. Dental care

3. Vision Care

4. Hearing Care

5. Preventive care: routine physical examinations, diagnostic tests and some immunizations

6. Care in custodial (not skilled) nursing homes

7. Hospital stays beyond the lifetime reserve of 150 days ${ }^{65}$

8. Physician charges above the "reasonable" rate reimbursed by Medicare Part B. ${ }^{66}$

\footnotetext{
${ }^{63}$ Beyond 90 days in the hospital, Medicare Part A provides a "lifetime reserve" of an additional 60 days that will be covered (with copayments) only once in a person's lifetime

${ }^{64}$ The regulation requires that the Medigap policy cover the 20 percent Part B copay for approved physician charges, subject to a maximum deductible of $\$ 200$ and a maximum benefit of no less than $\$ 5,000$ (in nominal dollars).

${ }^{65}$ The regulation requires that the Medigap policy pay $90 \%$ of coverage of stays above the lifetime reserve maximum for a lifetime maximum of 365 additional days.

66 The "reasonable charge" is defined as the lowest of the doctor's charge, the customary charge, or the prevailing charge in the area.
} 
Appendix B: Probit Estimates

Table B1: Probit Estimates of the Effect of the Minimum Standards on Non-Group Coverage Rates

(1)

(2)

(3)

\begin{tabular}{|c|c|c|c|}
\hline ADOPT & $\begin{array}{l}-0.052 * * * \\
(0.015)\end{array}$ & $\begin{array}{l}-\mathbf{0 . 0 5 5} * * * \\
(0.015)\end{array}$ & ------ \\
\hline ADOPT $^{1}$ & ------ & ----- & $\begin{array}{l}-0.050 * * * \\
(0.013)\end{array}$ \\
\hline ADOPT $^{2}$ & ------ & ------ & $\begin{array}{l}-\mathbf{0 . 0 8 1} * * * \\
(0.021)\end{array}$ \\
\hline
\end{tabular}

Notes: Coefficients are the estimated marginal effects from probit estimation, evaluated at the means of the independent variables. Columns (1) and (2) report results from estimation of equation (1) without and with covariates respectively. Column (3) reports results from estimation of equation (3) with covariates. See Table 2 for more details on the data and specification. *** denotes significance at the $1 \%$ level. $* *$ denotes significance at the $5 \%$ level. * denotes significance at the $10 \%$ level.

Table B2: Probit Estimates of Effect of Minimum Standards on Non-Mandated Benefit Coverage

\begin{tabular}{|c|c|c|c|}
\hline Benefit Coverage & $\begin{array}{l}\text { Difference-In- } \\
\text { Differences Without } \\
\text { Covariates } \\
\text { (1) }\end{array}$ & $\begin{array}{l}\text { Difference-in- } \\
\text { Differences with } \\
\text { Covariates } \\
\text { (2) }\end{array}$ & $\begin{array}{l}\text { Difference-in-Differences } \\
\text { with Covariates and } \\
\text { Interactions between } \\
\text { Covariates and AFTER } \\
\text { (3) }\end{array}$ \\
\hline Hospital Deductible & $\begin{array}{l}-0.041 \\
(0.035) \\
{[\mathrm{N}=1,042]}\end{array}$ & $\begin{array}{l}-0.044 \\
(0.036) \\
{[\mathrm{N}=889]}\end{array}$ & $\begin{array}{l}-0.016 \\
(0.019) \\
{[N=889]}\end{array}$ \\
\hline Physician Deductible & $\begin{array}{l}-0.192 * * * \\
(0.075) \\
{[\mathrm{N}=1,045]}\end{array}$ & $\begin{array}{l}-0.163 * * \\
(0.079) \\
{[N=943]}\end{array}$ & $\begin{array}{l}-0.172 * * \\
(0.082) \\
{[N=943]}\end{array}$ \\
\hline $\begin{array}{l}\text { Outpatient Prescription } \\
\text { Drug }\end{array}$ & $\begin{array}{l}-0.275^{* * *} \\
(0.071) \\
{[\mathrm{N}=1,130]}\end{array}$ & $\begin{array}{l}-0.302 * * * \\
(0.077) \\
{[\mathrm{N}=1,015]}\end{array}$ & $\begin{array}{l}-0.284 * * * \\
(0.082) \\
{[\mathrm{N}=1,015]}\end{array}$ \\
\hline $\begin{array}{l}\text { Care in Skilled Nursing } \\
\text { Home }\end{array}$ & $\begin{array}{l}-0.075 \\
(0.064) \\
{[\mathrm{N}=1,165]}\end{array}$ & $\begin{array}{l}-0.093 \\
(0.068) \\
{[\mathrm{N}=1,047]}\end{array}$ & $\begin{array}{l}-0.088 \\
(0.071) \\
{[N=1,047]}\end{array}$ \\
\hline $\begin{array}{l}\text { Inpatient Psychiatric } \\
\text { Care }\end{array}$ & $\begin{array}{l}-0.448 * * * \\
(0.040) \\
{[\mathrm{N}=1,165]}\end{array}$ & $\begin{array}{l}-0.453 * * * \\
(0.040) \\
{[\mathrm{N}=1,047]}\end{array}$ & $\begin{array}{l}-0.440 * * * \\
(0.043) \\
{[\mathrm{N}=1,047]}\end{array}$ \\
\hline Home Health Care & $\begin{array}{l}-0.297 * * * \\
(0.029) \\
{[\mathrm{N}=1,165]}\end{array}$ & $\begin{array}{l}-0.293 * * * \\
(0.029) \\
{[\mathrm{N}=1,047]}\end{array}$ & $\begin{array}{l}-0.277 * * * \\
(0.030) \\
{[N=1,047]}\end{array}$ \\
\hline
\end{tabular}

Note: Data are from the 1977 NMCES and 1987 NMES. Coefficients are the estimated marginal effects on AFTER*NONGROUP from probit estimation of equation (4), evaluated at the means of the independent variables. Different rows correspond to different dependent variables. Heteroscedasticity-adjusted standard errors are in parentheses. *** indicates significance at the $1 \%$ level; ** indicates significance at the $5 \%$ level; * indicates significance at the $10 \%$ level. 


\section{Appendix C: Effect of Minimum Standards in the Wilson (1977) model.}

The standard analysis of asymmetric information in insurance markets assumes perfectly competitive markets and individuals who differ only in their (privately known) probability of an accident. The Wilson (1977) "foresight" equilibrium is defined as follows:

Definition: A Wilson equilibrium is a set of policies such that when consumers choose contracts to maximize expected utility, each policy earns non-negative profits individually and there is no other set of policies outside of the equilibrium set which, if offered, would earn positive profits in the aggregate and non-negative profits individually, after the unprofitable policies in the original set have been withdrawn.

The italicized portion represents the refinement of the Rothschild and Stiglitz (1976) equilibrium definition; the refinement guarantees existence and allows for the possibility of a pooling equilibrium.

Figure C1 illustrates the effects of imposing a minimum standard in a Wilson (1977) separating equilibrium. The vertical and horizontal axes indicate, respectively, income in states with and without an accident. The point E represents the individual's endowment with no insurance. The 45 degree line represents points of full insurance. Movements to the northeast indicate increasing utility. The line HE (LE) represents the set of policies that earn zero expected profits when high (low) risk individuals buy them. High risk individuals purchase policy $\alpha_{H}$ and get full insurance at their actuarially fair price; low risk individuals purchase policy $\alpha_{\mathrm{L}}$, which is the maximum amount of insurance they can purchase at their actuarially fair price while maintaining incentive compatibility for the high risk type. As drawn, the equilibrium is separating rather than pooling because low risk individuals prefer their allocation $\alpha_{\mathrm{L}}$ to their most-preferred outcome on the market odds line EF, which is given by $\gamma$.

The minimum standards then require that all individuals who purchase insurance must purchase at least the minimum amount $m$, which exceeds the amount of insurance low risk types receive with $\alpha_{\mathrm{L}}$. Therefore, the low risk type must choose between purchasing either the minimum insurance amount $m$ on the high risk indifference curve through $\alpha_{H}$ or his most preferred outcome on the market odds line, which is given by $\gamma$. As drawn, low risk individuals prefer the latter and the result is a pooling equilibrium with both types buying policy $\gamma$. There is no profitable deviation from $\gamma$ which remains profitable after the unprofitable contracts are withdrawn. By the single crossing property, there are policies above EF and below EL which, if offered in addition to $\gamma$, would attract low risk types and not high risk types and thus 
earn positive profits. However, once this is offered, policy $\gamma$-- which now attracts only the high risk types - becomes unprofitable and would be withdrawn; high risk types would then purchase the remaining policy, making it unprofitable. Thus sufficiently high minimum standards can result in the destruction of a separating equilibrium and a resulting pooling equilibrium in which the market for very comprehensive policies has been destroyed. ${ }^{67}$

With the move from a separating equilibrium to a pooling equilibrium, low risk types who remain in the market gain insurance and high risk types lose insurance. Low risk types are worse off, since by definition they preferred the original separating equilibrium to any outcome on the pooling line. As a result, some may choose to purchase no insurance rather than comply with the minimum standards. High risk types are better off by revealed preference; they could have continued to purchase their policy in the separating equilibrium. The model is therefore consistent with the empirical findings that the minimum standards are associated with a decline in both the proportion of the population purchasing insurance and the purchase of non-mandated insurance by those who retain insurance coverage.

Welfare analysis can be made conceptually simpler by recognizing that the change in the prices of insurance associated with moving from a separating to a pooling equilibrium represents a transfer between risk types and so - with a social welfare function that weights both types equally - is irrelevant for welfare calculations. ${ }^{68}$ In the separating equilibrium, high risk types have optimal (full) insurance while low risk types are constrained from buying their optimal (full) insurance. Therefore, from a social welfare perspective, the loss in insurance by low risk types who drop coverage and high risk types who drop some non-mandated coverage represents a welfare loss while the gain in insurance for low risk types who upgrade their policies to comply with the minimum represents a welfare gain.

\footnotetext{
${ }^{67}$ Indeed, if the minimum required insurance exceeds the amount $\gamma$ that low risk types wish to buy at the market odds price, the result is a pooling equilibrium at the minimum requirement and a complete destruction of the market for any more comprehensive coverage.

${ }^{68}$ The model makes stark predictions about the risk type of individuals who experience various changes, with low risk individuals dropping coverage and high risk individuals dropping non-mandated benefits. Such selection effects only impact social welfare analysis, however, if the different risk types - which reflect differences in expected medical expenditure levels - have systematic differences in the variance in medical expenditure around its mean. Estimates of the coefficient of variation on total medical expenditure for individuals age 65 and older in the 1977 NMCES indicate no systematic differences by health status.
} 


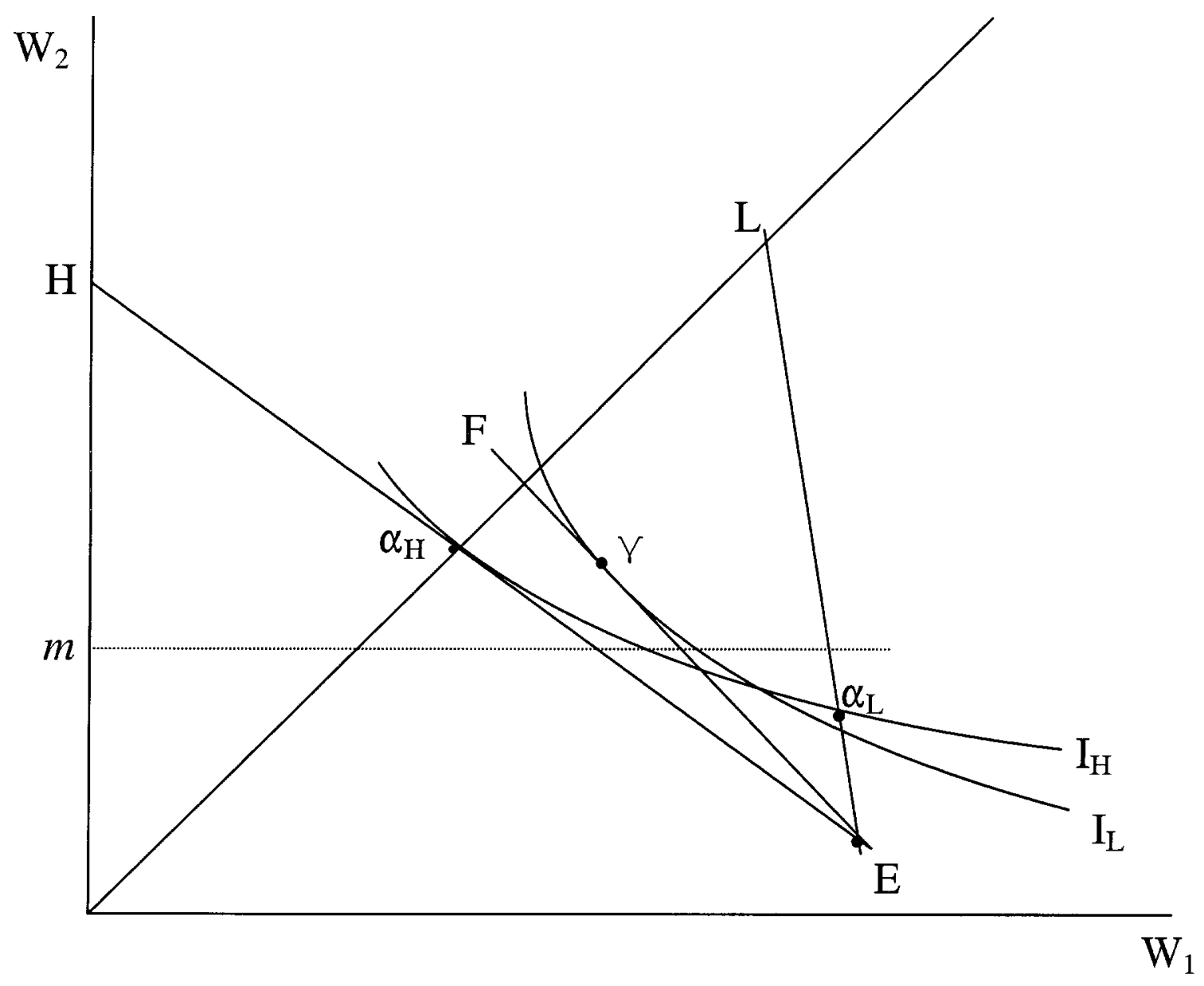

Figure C1: Minimum Standards in the Wilson (1977) Model 